\title{
NLRP3 and ASC suppress lupus-like autoimmunity by driving the immunosuppressive effects of TGF- $\beta$ receptor signalling
}

\author{
Maciej Lech, Georg Lorenz, Onkar P Kulkarni, Marian 00 Grosser, Nora Stigrot, \\ Murthy N Darisipudi, Roman Günthner, Maximilian W M Wintergerst, David Anz, \\ Heni Eka Susanti, Hans-Joachim Anders
}

Handling editor Tore K Kvien

- Additional material is published online only. To view please visit the journal online (http://dx.doi.org/10.1136/ annrheumdis-2014-205496).

Medizinische Klinik und Poliklinik IV, Klinikum der Ludwig Maximilians Universität, MünchenInnenstadt, Munich, Germany

\section{Correspondence to} Professor Hans-Joachim Anders, Medizinische Klinik und Poliklinik IV, Ludwig Maximilians Universität München, Ziemssenstr. 1, München 80336, Germany; hjanders@med.uni-muenchen. de

$\mathrm{ML}$ and $\mathrm{GL}$ contributed equally.

Received 3 March 2014 Revised 14 July 2014 Accepted 30 July 2014 Published Online First 18 August 2014

\section{ABSTRACT}

Objectives The NLRP3/ASC inflammasome drives host defence and autoinflammatory disorders by activating caspase-1 to trigger the secretion of mature interleukin (IL)-1B/L-18, but its potential role in autoimmunity is speculative.

Methods We generated and phenotyped N/rp3deficient, Asc-deficient, II-1r-deficient and II-18-deficient C57BL/6-Ipr/lpr mice, the latter being a mild model of spontaneous lupus-like autoimmunity.

Results While lack of IL-1R or IL-18 did not affect the C57BL/6-Ipr/lpr phenotype, lack of NLRP3 or ASC triggered massive lymphoproliferation, lung T cell infiltrates and severe proliferative lupus nephritis within 6 months, which were all absent in age-matched C57BL/ 6-Ipr/Ipr controls. Lack of NLRP3 or ASC increased dendritic cell and macrophage activation, the expression of numerous proinflammatory mediators, lymphocyte necrosis and the expansion of most $T$ cell and $B$ cell subsets. In contrast, plasma cells and autoantibody production were hardly affected. This unexpected immunosuppressive effect of NLRP3 and ASC may relate to their known role in SMAD2/3 phosphorylation during tumour growth factor (TGF)- $\beta$ receptor signalling, for example, N/rp3-deficiency and Asc-deficiency significantly suppressed the expression of numerous TGF- $\beta$ target genes in C57BL/6-Ipr/pr mice and partially recapitulated the known autoimmune phenotype of Tgf- $\beta 1$-deficient mice.

Conclusions These data identify a novel non-canonical immunoregulatory function of NLRP3 and ASC in autoimmunity.

\section{INTRODUCTION}

Systemic lupus erythematosus (SLE) is a paradigmatical form of systemic autoimmunity. ${ }^{1}$ SLE is based on genetic variants that compromise lymphocyte death and their silent clearance. ${ }^{2}$ In SLE, aberrant lymphocyte death triggers sterile inflammation, costimulation and, subsequently, autoimmunisation against nuclear autoantigens. ${ }^{3}$ This process is driven by the adjuvant effect of endogenous nucleic acids at Toll-like receptor (TLR)-7 and TLR-9 that trigger interferon- $\alpha$-dependent immunity. ${ }^{4}$ Lupus nephritis results from immune complex disease and is associated with progressive infiltrates of autoreactive $\mathrm{T}$ cells, often forming tertiary lymphoid tissue organs like in other solid organs. ${ }^{1} 67$
Inflammasomes are danger signalling platforms within the cytosol of myeloid antigen-presenting cells that integrate various pathogen-associated or damage-associated signals into the activation of caspase- $1{ }^{8}$ The NACHT, LRR and PYD domains-containing protein (NLRP)-3 inflammasome is comprised of NLRP3 and of apoptosisassociated speck-like protein containing a CARD (ASC), which first interact at their caspase recruitment domain (CARD) followed by the assembly of several such heterodimers to a wheel-like structure that can activate caspase- $1 .^{8}$ Caspase- 1 activation has two major biological effects that relate to its enzymatic activity: First, it cleaves pro-interleukin (IL)- $1 \beta$ and pro-IL-18 into its mature forms. The pyretic and proinflammatory effects of IL- $1 \mathrm{R}$ and IL-18R signalling imply an important role for caspase-1 activation in host defence as well as in autoinflammation disorders. ${ }^{8-11}$ In addition, crystals or crystalline proteins specifically activate the NLRP3 inflammasome, which unravelled the central role of caspase-1-mediated inflammation in crystal-related disorders. ${ }^{12-16}$ The second biological effect of caspase- 1 is DNA fragmentation and programmed cell death, referred to as pyroptosis. ${ }^{17} 18$

While the role of the NLRP3 inflammasome in host defence and autoinflammation is obvious, its role in autoimmunity is less clear, mostly because IL-1 $\beta$ and IL-18 have diverse effects on the adaptive immune system. ${ }^{19}$ Some studies support a similar proinflammatory effect on adaptive immunity, as IL-1 $\beta$ and IL-18 promote the proliferation and survival of Th1 and Th17 T cells and B cells, ${ }^{19} 20$ and Nlrp3-deficient and Asc-deficient mice are resistant to experimental autoimmune encephalitis. ${ }^{21} 22$ In contrast, NLRP3 overexpression does not induce autoimmunity, ${ }^{23}{ }^{24}$ and therapeutic IL-1 blockade does not consistently improve experimental and human systemic autoimmunity in a clinically meaningful manner, for example, in systemic lupus. ${ }^{25-28}$

Given its dominant proinflammatory role in innate immunity one would predict that the NLRP3 inflammasome will drive antigenpresentation, $\mathrm{T}$ cell priming, lymphocyte proliferation and finally, autoimmune tissue inflammation. ${ }^{29}{ }^{30}$ Furthermore, nuclear lupus autoantigens and neutrophil extracellular traps potentially contribute to lupus activity by their NLRP3 agonistic effect. $^{31-33}$ To test this concept, we generated 
Nlrp3-deficient, Asc-deficient, Il-1r-deficient and Il18-deficient C57BL/6-lpr/lpr $\left(\mathrm{B} 6^{l p r}\right)$ mice. Female $\mathrm{B} 6^{l p r}$ mice represent a mild model of spontaneous lupus-like autoimmunity or autoimmune lymphoproliferative syndrome ${ }^{34}$ that has proven suitable to identify functional roles of immunoregulatory elements in systemic autoimmunity. ${ }^{35-39}$ We hypothesised that based on the concept of canonical NLRP3 inflammasome signalling Nlrp3-deficient, Asc-deficient, $I l-1 r$-deficient and Il18-deficient $\mathrm{B} 6^{l p r}$ mice would display attenuated SLE, a hypothesis disproved by our data.

\section{MATERIALS AND METHODS}

\section{Animal studies}

Nlrp3-deficient and Asc-deficient mice were generated and backcrossed (F10) to the C57BL/6 strain as described. ${ }^{14} 40$ $\mathrm{Il}$-1r-deficient and $\mathrm{Il}$-18-deficient mice in the same genetic background were obtained from Jackson Laboratories (Bar Harbour Maine). Nlrp3-deficient and Asc-deficient mice as well as $\mathrm{B} 6^{l p r / l p r}$ mice $\left(\mathrm{B} 6^{l p r}\right.$ ) were obtained from Jackson Laboratories (Bar Harbour, Maine). Each strain was mated with $\mathrm{B} 6^{l p r}$ mice to generate double heterozygote mice, which were then mated among each other to generate double homozygous knockout and $\mathrm{B} 6^{\text {pr }}$ control mice. In each individual mouse, the genotype was assured by PCR. Mice were housed in groups of five in sterile filter top cages with a $12 \mathrm{~h}$ dark/light cycle and unlimited access to autoclaved food and water. All mice were sacrificed by cervical dislocation at 24 weeks of age. All experimental procedures were performed according to the German animal care and ethics legislation and had been approved by the local government authorities.

\section{Evaluation of autoimmune tissue injury}

Spleens, lymph nodes, lungs and kidneys from all mice were fixed in $10 \%$ buffered formalin, processed and embedded in paraffin. The severity of the renal lesions was graded on periodic acid-Schiff stained sections using the indices for activity and chronicity as described. ${ }^{41}$ Lung and kidney fibroses were assessed by Masson-Trichrom staining. Immunostaining was performed as described ${ }^{42}$ using the following primary antibodies: antimouse $\operatorname{IgG}$ and antimouse $\operatorname{IgM}$ (1:100, M32015, Caltag Laboratories, Burlingame, California, USA), antimouse C3c (complement, GAM/C3c/FITC, Nordic Immunological Laboratories, Tilburg, Netherlands, 1:200), antimouse CD11c (BD), antimouse CD19 (antibody-online.de), antimouse CD45 (BD), antimouse MAC2 (Cedarlane, Eching, Germany), antimouse Ki67 (Dako Cytomatic, Hamburg, Germany) and antimouse neutrophil (AbD SeroTec). Negative controls included incubation with a respective isotype antibody. For quantitative analysis, glomerular cells were counted in 10 cortical glomeruli per section. Immunostainings of lungs and spleens were analysed using Adobe Photoshop CS4 extended for area calculation. Serum creatine levels were determined using Jaffe method (DiaSys Diagnostic Systems). Albuminuria was determined via mouse Albumin Quantification Set (Bethyl Laboratories, Montgomery, Texas, USA). Cleaved caspase-3 staining was done on paraffin-embedded sections using cleaved caspase-3 (Asp175) antibody (\#9661, Cell signalling) in combination with antirabbit biotin and Strept-Alexa-Fluor (Vector Laboratories Burlingame, California, USA).

\section{Flow cytometry}

Antimouse CD3, CD4, CD8, CD25 (BD Pharmingen, Heidelberg, Germany), foxP3 (BioLegend, San Diego, USA), CD11c (BD), F4/80 (AbDSeroTec, Düsseldorf, Germany), CD19
(AbD), B220, CD21, CD23, IgD and IgM, antimouse $\kappa$ light chain and CD138 (BD) have been stained to differentiate T cell and $\mathrm{B}$ cell subsets as well as dendritic cells and macrophages. Major histocompatibility complex II (MHCII), (eBioscience, San Diego, USA), CD44, CD86 (BD) and CD69 (Caltag Laboratories, Buckingham, UK) were used as activation markers. Intracellular labelling (foxP3 and $\kappa$ light chain) was done using Cytofix/Cytoperm kit

(BD), following the manufacturer's instructions. Each immune cell subset was defined at least by two different markers. Annexin/ propidium iodide fluorescence-activated cell sorting (PI FACS) was performed with annexinV-FITCapoptosis-detection-kit (BD-Bioscience) following the manufacturer's instructions. Respective isotype antibodies were used to demonstrate specific staining of cell subpopulations. Cell counting beads (Invitrogen) were used for determining cell numbers by FACS.

\section{Real-time quantitative PCR}

Real-time RT-PCR was performed on total spleen mRNA as previously described. ${ }^{43}$ SYBR Green Dye detection system was used for quantitative RT-PCR on Light Cycler 480 (Roche, Mannheim, Germany). Gene-specific primers (300 nM, Metabion, Martinsried, Germany) were used as listed in online supplementary table S1. Controls consisting of ddH2O were negative for target and housekeeper genes. 18S rRNA was used as a housekeeper. The PCR Arrays were performed in both 96-well plates according to the manufacturer's protocol (Quiagen, SABiosciences, Germany). Five housekeeping genes including actin $\beta, \beta-2$ microglobulin, glyceraldehyde-3phosphate dehydrogenase, $\beta$-glucuronidase and heat shock protein $90 \alpha$ (cytosolic), class B member 1 were used. Standard controls on each array for genomic DNA contamination, RNA quality and general PCR performance were included.

\section{Autoantibody and plasma cytokine analysis}

Serum (auto-) antibody levels were determined by ELISA as described. ${ }^{37} 44$ C57BL/6 10 week mouse serum was used as negative control. The horseradish peroxidase (HRP) conjugated antimouse IgG was used as secondary antibody. Serum cytokine levels and cell culture supernatants were determined using the commercial ELISA kits.

\section{In vitro experiments}

Bone marrow cells from wild type and knockout mice were cultured with $20 \mathrm{ng} / \mathrm{mL}$ mouse recombinant granulocytemacrophage colony-stimulating factor (GM-CSF)/M-CSF (R\&D Systems, Wiesbaden, Germany) in Roswell Park Memorial Institute (RPMI) medium for 7 days to generate $>90 \%$ CD11c dendritic cell subsets (DCs). On day 7 , cells were harvested, suspended in fresh medium and seeded at $1 \times 10^{6}$ cells/well; $1500 \mu \mathrm{L} /$ well in 12-well plates. Stimuli were ultrapure lipopolysaccharide (LPS) $1 \mu \mathrm{g} / \mathrm{mL}$ (Invivogen, San Diego, California, USA), CpG-DNA $166810 \mu \mathrm{g} / \mathrm{mL}$ (Invivogen, San Diego, California, USA), imiquimod $1 \mu \mathrm{g} / \mathrm{mL}$ (Sequoia Research Products Ltd, Oxford, UK) and CpG (ODN 1668; Invivogen, San Diego, USA) for $24 \mathrm{~h}$. TGF- $\beta$ ( $1 \mathrm{ng} / \mathrm{mL}$ R\&D Systems, Minneapolis, Minnesota, USA) stimulation of bone marrowderived dendritic cells (BMDCs) was done for 30-45 min before they were harvested in radioimmunoprecipitation assay (RIPA) buffer, supplemented with phosphatase inhibitor cocktail (Sigma Aldrich, St Louis, USA) and complete protease inhibitor cocktail (Roche, Germany). CD19 B cells were isolated from spleens of female B $6^{l p r}$ mice using B Cell Isolation Kit, followed 
by depletion of dead cells via the dead cell removal kit (Miltenyi, Bergisch Gladbach, Germany). Purity as determined by FACS analysis revealed over $80 \%$ purity for each isolate. Total thymocytes were isolated according to standard protocols from control and Nlrp3-deficient or Asc-deficient B6 ${ }^{1 \mathrm{pr}}$ mice. For the differentiation of FoxP3 + regulatory $\mathrm{T}$ cells, CD4CD $25^{\text {negative }}$ cells were purified from the spleen by two-step magnetic cell sorting (MiltenyiBiotec). Cells were cultured in complete RPMI medium with $0.0001 \%$ of 2 -mercaptoethanol in flat bottom 24 -well plates $\left(1 \times 10^{6}\right.$ cells in $1 \mathrm{~mL}$ ) and activated with anti-CD3-CD28 beads (Invitrogen, Darmstadt, Germany) at a bead-to-cell ratio of 1:5 in the presence of TGF- $\beta \quad(5 \mathrm{ng} / \mathrm{mL}, \quad \mathrm{R} \& \mathrm{D}$ Systems, Minneapolis, Minnesota, USA) and IL-2 (10 ng/mL, Peprotech Hamburg, Germany). After $72 \mathrm{~h}$, the cells were stained with antimouse CD4-PE (BD) and antimouse FoxP3-Pacific Blue (eBioscience) antibodies for flow cytometry analysis. FoxP3 was detected using the eBioscience Treg cell staining kit. Analysis was performed using an FACS Canto II flow cytometer (BD) and FlowJo software (TreeStar, Ashland, Oregon, USA). For analysis of regulatory $\mathrm{T}$ cell function $5 \times 10^{4} \mathrm{CD} 4 \mathrm{CD} 25^{\text {negative }} \mathrm{T}$ effector cells were co-incubated with either $5 \times 10^{3}$ or $5 \times 10^{4}$ CD4CD25 regulatory $\mathrm{T}$ cells in the presence of $5 \times 10^{4} \mathrm{CD} 4$-depleted splenocytes for 3 days. Expression of CD69 on T cells and secretion of IL-2 was determined by flow cytometry and ELISA, respectively. SMAD2/3 translocation in DCs was assessed after the staining procedure with anti-SMAD2/3 (Cell signalling, Boston, Massachusetts, USA) following $45 \mathrm{~min}$ of stimulation with TGF- $\beta$ and compared using Adobe Photoshop CS4 Extended.

\section{Western blotting}

Proteins were extracted from whole spleen lysates or cultured BMDCs homogenised in RIPA buffer (Sigma Aldrich) containing phosphatase and proteinase inhibitor. Sodium dodecyl sulfate polyacrylamide gel electrophoresis and western blotting were performed following standard procedures, using rabbit antiphosphoSMAD2 (Ser465/467), anticleaved-caspase-3 (Cell Signalling, Danvers, USA) or rabbit anticaspase-1 (Santa Cruz, Heidelberg, Germany) as primary antibodies. The signal of rabbit anti- $\beta$-actin monoclonal antibody (Cell Signalling) served as a loading control. Secondary antibody incubation was done with HRP conjugated antirabbit IgG (Cell Signalling) prior to detection with enhanced chemiluminescence plus chemiluminescent kit (GE Healthcare Life Sciences, Freiburg, Germany).

\section{Statistical analysis}

One-way analysis of variance followed by post hoc Bonferroni's test was used for multiple comparisons using GraphPad Prism V.4.03. Single groups were compared by unpaired two-tailed Student $t$ test. Data were expressed as mean \pm SEM. Statistical significance was set at a p value of $<0.05\left({ }^{*}\right)$; p value of $<0.01$ $(* *)$; p value of $<0.001(* * *)$ in comparison with control animals.

\section{RESULTS}

\section{NLRP3 and ASC, but not IL-1R and IL-18, protect B6 ${ }^{\text {Ipr }}$ mice from kidney and lung injury}

Lupus nephritis is the most common organ manifestation of $\mathrm{SLE}^{1}$ and $\mathrm{B} 6^{l p r}$ mice develop mild glomerulonephritis. ${ }^{34}$ Lack of NLRP3, ASC, IL-1R or IL-18 alone did not cause any kidney phenotype up to 12 months of age. We generated Nlrp3-deficient, Asc-deficient, $I l$-1-deficient $r$ and $I l$-18-deficient $\mathrm{B} 6^{l p r}$ mice that bred at Mendelian ratios and common litter sizes. At 6 months of age Nlrp3-deficient and Asc-deficient $6^{l p r}$ mice revealed diffuse mesangioproliferative glomerulonephritis and periglomerular inflammation in kidneys of $\mathrm{B} 6^{l p r}$ mice, while lack of IL-1R or IL-18 had no effect on kidney disease (figure 1). The composite activity score for lupus nephritis was significantly increased only in $\mathrm{B} 6^{l p r} A s c-1-$ and $\mathrm{B} 6^{l p r} \mathrm{Nlrp3}-1-$ mice (figure $1 \mathrm{~B}$ ) and there was a non-significant trend towards more albuminuria (see online supplementary figure S1A). CD45 cell and Mac2 macrophage numbers inside the glomerular tufts were significantly increased in these mutant strains only (figure 1A, C, D). Only B6 ${ }^{l p r}$ Nlrp3-/- and $\mathrm{B} 6^{l p r}$ Asc-/- mice showed increased glomerular deposits of complement factor $\mathrm{C} 3 \mathrm{c}$ and intrarenal mRNA expression of tumour necrosis factor (TNF)- $\alpha$ (not shown, figure 1E), although glomerular IgG deposits remained unaffected (figure $1 \mathrm{~F}$ ). Serum creatine levels were increased only in $\mathrm{B} 6^{l p r}$ Asc-/- and $\mathrm{B} 6^{l p r}$ Nlrp3-/- mice, although this reached statistical significance only for Nlrp3-deficiency (figure 1G). Lung disease is another organ manifestation of SLE in humans ${ }^{1}$ but usually does not affect B6 ${ }^{l p r}$ mice. $^{34}$ Nevertheless, Nlrp3-deficient as well as Asc-deficient $\mathrm{B}^{l p r}$ mice developed significant peribronchial mononuclear CD3 T cell infiltrates, while these were absent in wild type $\mathrm{B} 6^{l p r}$ mice and $I l-1 r$-deficient and $I l 18$-deficient $\mathrm{B} 6^{l p r}$ mice (see online supplementary figure S2A, B). Neither kidneys nor lungs developed significant interstitial fibrosis in any of the mouse strains (see online supplementary figure S1B) and also the low neutrophil numbers as well as IL-17 gene mRNA expression levels were genotype-independent (see online supplementary figure S3A-D). Together, lack of NLRP3 or ASC aggravates autoimmune nephritis and lung disease in $\mathrm{B} 6^{l p r}$ mice, while $I l-1 r$-deficient and $I l$-18-deficient $\mathrm{B} 6^{l p r}$ mice displayed no such phenotype. These findings imply an immunoregulatory role of ASC and NLRP3 in systemic autoimmunity that is independent of IL-1 and IL-18.

\section{NLRP3 and ASC, but not IL-1R and IL-18, suppress lymphoproliferation in $\mathrm{B}^{\text {Ipr }}$ mice}

To unravel this unexpected finding, we first evaluated Nlrp3-deficient, Asc-deficient, $\mathrm{Il}$-1r-deficient and $\mathrm{Il}$-18-deficient mice for spontaneous autoimmunity, but up to 6 months of age antinuclear antibodies, anti-dsDNA IgG or rheumatoid factor could not be detected (not shown). Flow cytometry profiling of spleen monocyte and lymphocyte populations did not reveal any differences between the genotypes at 6 weeks and 24 weeks of age (not shown). Next we carefully assessed the Nlrp3-deficient, Asc-deficient, $\mathrm{Il}$-1r-deficient and $\mathrm{Il}$-18-deficient B $6^{l p r}$ mice. Consistent with a dysfunctional inflammasome, Nlrp3-deficient or Asc-deficient dendritic cells or macrophages of B6lpr mice secreted reduced amounts of IL-1 $\beta$ in vitro (see online supplementary figure S3). In addition, activated caspase- 1 mRNA and protein levels were strongly reduced in spleens of Nlrp3-deficient and Asc-deficient B $6^{l p r}$ mice as compared with those of $\mathrm{B}^{l p r}$ control mice (figure $2 \mathrm{~A}, \mathrm{D}$ ). This was remarkable as other cell death-related mRNAs were increased in these two mouse strains (figure 2A). Caspase-3 mRNA showed the strongest induction but caspase- 3 protein cleavage was not increased in western blots of spleen isolates (figure 2D). Similarly, immunostaining or cleaved caspase-3 positive splenocytes did not reveal any differences among the genotypes (see online supplementary figure S5A), arguing against enhanced splenocyte apoptosis in Nlrp3-deficient or Asc-deficient $\mathrm{B}^{l p r}$ mice. In fact, annexin IV flow cytometry revealed that splenocyte apoptosis remained unaffected by the genotype (see online supplementary figure S5B). However, lack of NLRP3 and ASC caused massive splenomegaly and lymphadenopathy at 6 months of age, while 


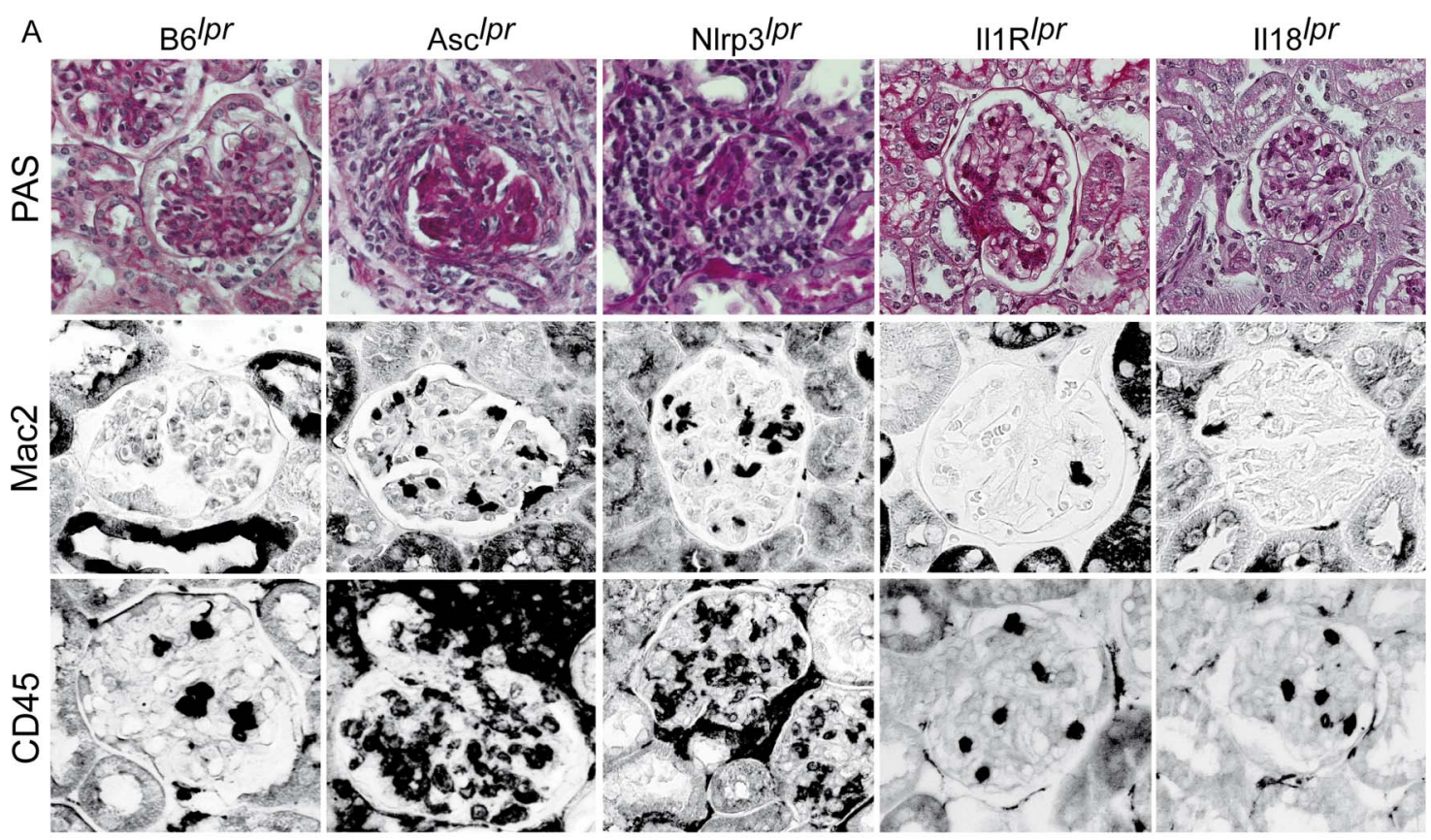

B

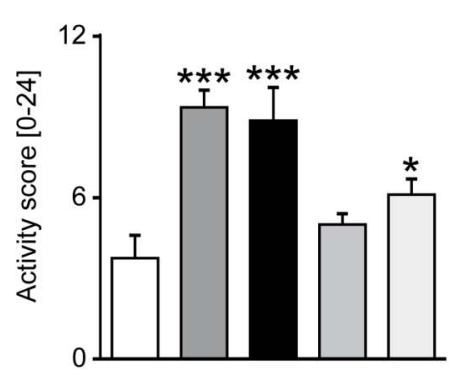

E

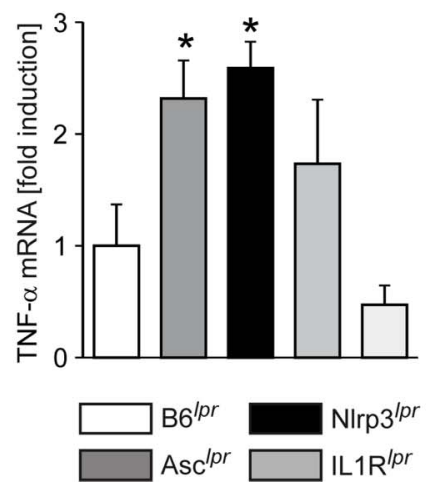

C

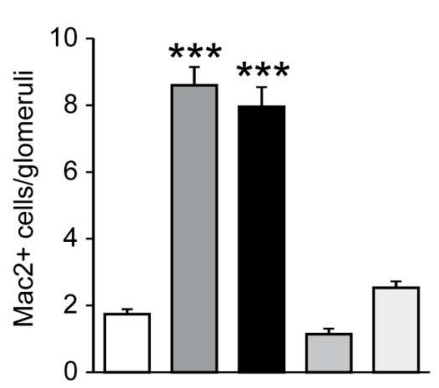

$\mathrm{F}$

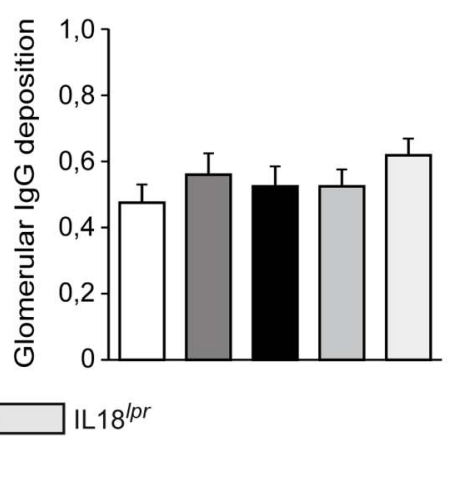

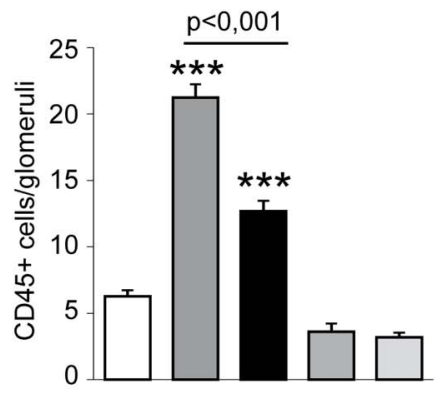

G

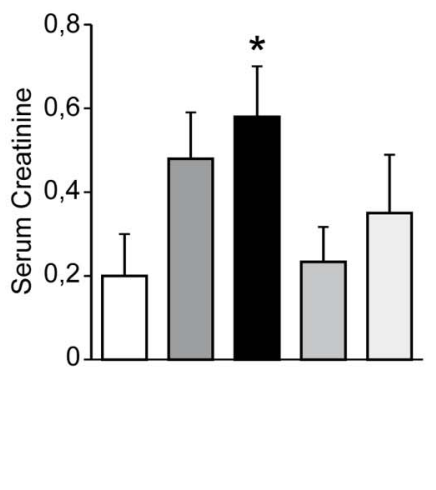

Figure 1 Immune complex nephritis in B6 ${ }^{I p r}$ mice. (A and B) Renal sections were stained with periodic acid-Schiff (PAS) or Mac2 antibodies and signal intensity was scored applying a semiquantitativem score or quantified in glomeruli, respectively. Data are shown as means of at least 40 scored hpf from at least eight mice in each group; ${ }^{*} \mathrm{p}<0.05,{ }^{* * *} \mathrm{p}<0.001$. (C) Kidney mRNA was isolated from $\mathrm{B} 6^{\text {lpr }} / \mathrm{Asc}-/-, \mathrm{B} 6^{\text {lpr }} / \mathrm{Nlrp3}-1-, \mathrm{B} 6^{/ p r} /$ II-18-I-, B $6^{/ p r} / \mathrm{ll}-1 \mathrm{r}-1-$ and $\mathrm{B} 6^{/ p r}$ mice. mRNA levels in kidney were analysed for tumour necrosis factor (TNF)- $\alpha$. Data are shown as means of the ratio of the specific mRNA versus that of $18 \mathrm{~S}$ rRNA, ${ }^{*} p<0.05$. (D) Renal sections immunostaining-score was also performed for immunoglobin $G$ (IgG). Data are shown as means of quantification of at least 40 glomeruli from at least eight mice in each group; ${ }^{*} p<0.05$. (E) Serum creatine was measured in all three groups of mice. The histogram presents means \pm SEM of at least 10 mice in each group, ${ }^{*} p<0.05$ versus $B 6^{1 p r}$ mice.

total body weight was phenotype-independent (figure $2 \mathrm{~B}, \mathrm{C}$ ). Spleen Ki-67 staining displayed a massive increase in spleen cell proliferation in Nlrp3-deficient and Asc-deficient $\mathrm{B} 6^{l p r}$ mice compared with $\mathrm{B}^{l p r}$ controls (see online supplementary figure $\mathrm{S} 5 \mathrm{C})$. This was consistent with increased total numbers of spleen and lymph node cells quantified by flow cytometry, while leucocyte subset percentages remained constant (data not shown). Thus, Nlrp3-deficiency, Asc-deficiency, Il-1r-deficiency and $\mathrm{Il}$-18-deficiency do not cause autoimmunity by itself, but aggravated nephritis in $\mathrm{B} 6^{l p r}$ mice lacking only NLRP3 or ASC 


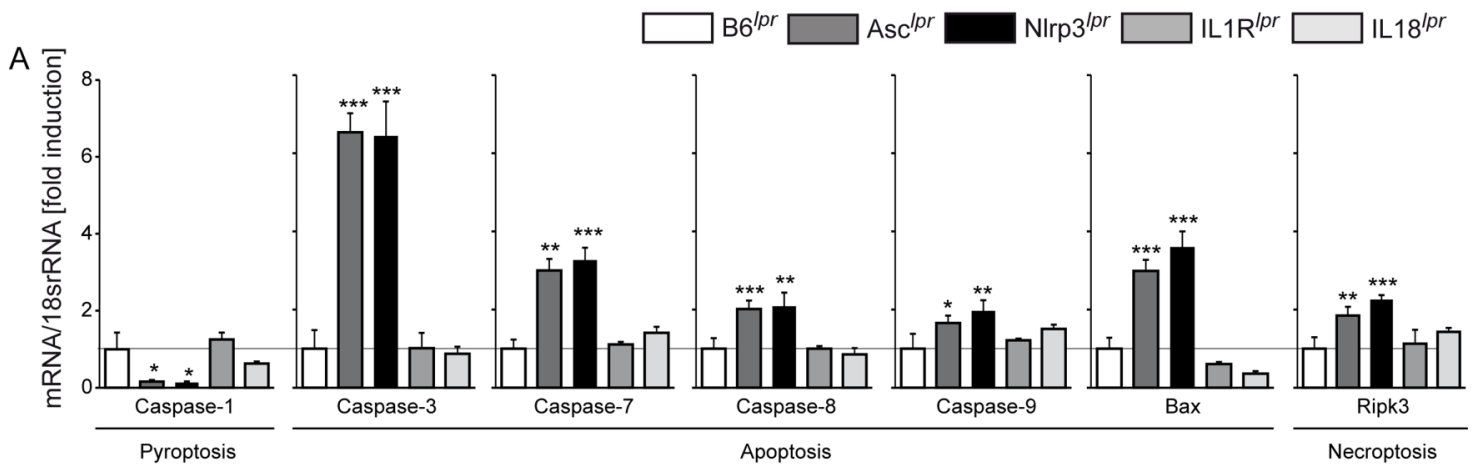

B

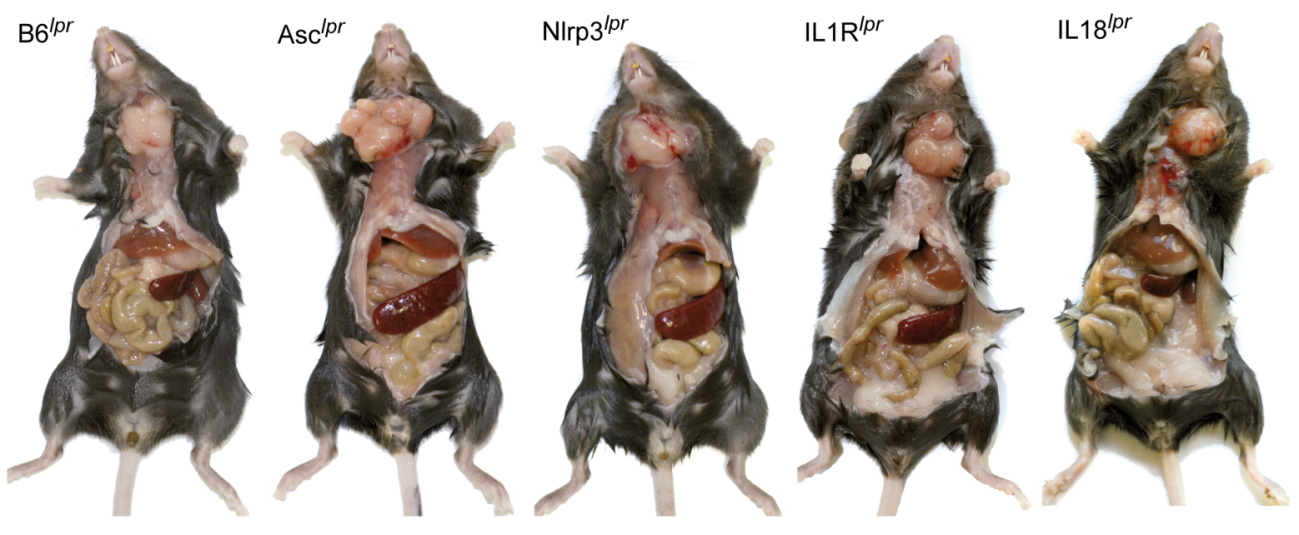

C

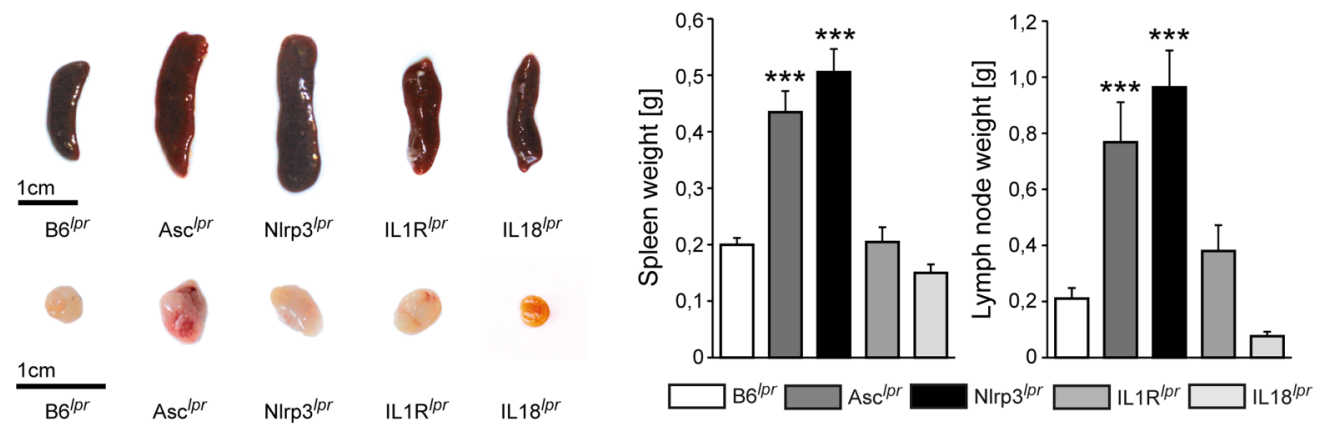

D
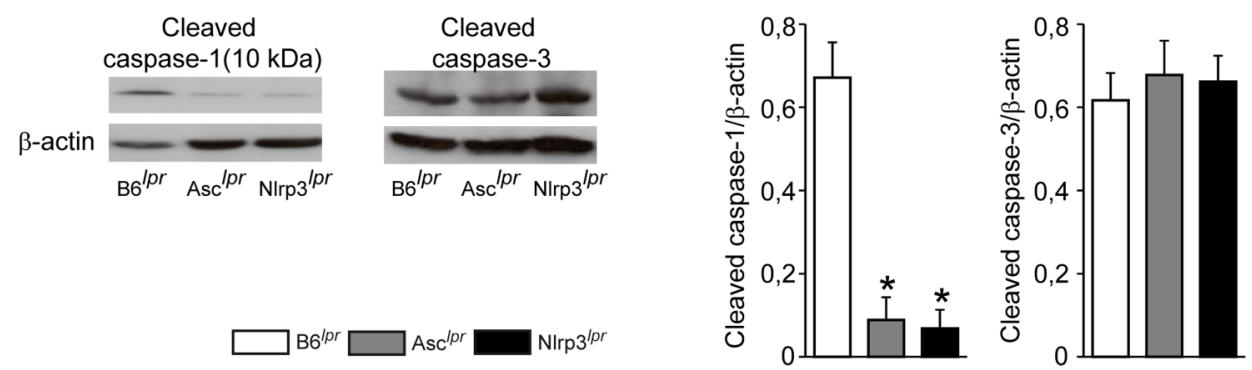

Figure 2 Lack of apoptosis-associated speck-like protein containing a caspase recruitment domain (ASC) or NACHT, LRR and PYD

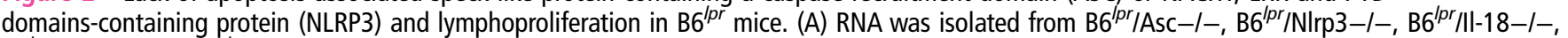
$\mathrm{B}^{/ p r} / \|-1 \mathrm{r}-I-$ and $\mathrm{B} 6^{/ p r}$ mice for real-time PCR analysis. Data are expressed as means of the ratio of the specific mRNA versus that of $18 \mathrm{~S}$ rRNA ${ } \mathrm{SEM}$ and presented as fold induction to $\mathrm{B} 6^{\mathrm{lpr}}$ gene expression level; ${ }^{*} \mathrm{p}<0.05 ;{ }^{* *} \mathrm{p}<0.01 ;{ }^{* * *} \mathrm{p}<0.001$ versus $\mathrm{B} 6^{\text {/pr }}$ mice. (B and C) At 6 months of age Asc-deficient and NIrp3-deficient B6 $6^{\text {pr }}$ but not II-18-deficient and II-1R-deficient $B 6^{\text {Ipr }}$ mice revealed massive hyperplasia of cervical, axillar and mesenteric lymph nodes as well as splenomegaly. Data are means \pm SEM from at least 15 mice in each group, ${ }^{*} p<0.05$; ${ }^{* * *} p<0.001$. Images of $B$ and $C$ are representative for at least 15 mice in each group. (D) Protein samples were prepared from spleens of 6 month-old $B 6^{/ p r} / A s c-I-, B 6^{/ p r} /$ Nlrp3-I- and B6 $6^{\text {Ipr }}$ mice. Cleaved caspase- 1 and cleaved caspase-3 western blots indicate the quantitative (50 $\mu \mathrm{g}$ protein load per lane) protein expression. Histograms represent the ratio of cleaved caspase- 1 and cleaved caspase- 3 to the respective $\beta$-actin expression. Data are means \pm SEM from at least three independent experiments, ${ }^{*} \mathrm{p}<0.05$ versus $\mathrm{B}^{\prime \text { pr }}$ mice. 
was associated with hyperproliferation of lymphocytes despite lack of caspase- 1 activation and was independent of IL-1R and IL-18. Impaired lymphocyte apoptosis could be excluded as a causative mechanism for this phenotype (see online supplementary figure S5B).

\section{NLRP3 and ASC suppress the activation of} antigen-presenting cells in $\mathrm{B}^{l p r}$ mice

Given the proinflammatory effects of the NLRP3 inflammasome in innate immunity, ${ }^{8} 45$ we expected less activation of dendritic cells and macrophages in mice. However, spleen cell flow cytometry rather revealed an expansion of activated (MHC II+)
CD11c cells and F4/80+ cells in Nlrp3-deficient or Asc-deficient $\mathrm{B} 6^{l p r}$ mice (figure $3 \mathrm{~A}$ and see online supplementary figure $\mathrm{S} 6 \mathrm{~A}$ ). This was associated with increased mRNA expression levels of numerous NF- $\kappa \mathrm{B}$-dependent proinflammatory mediators (figure 3B). TLR signalling per se was not genotype-dependent. TNF- $\alpha$ induction in spleen dendritic cells upon stimulation with agonists to TLR4, TLR7 and TLR9 for $24 \mathrm{~h}$ was identical for all genotypes (figure $3 \mathrm{C}$ ). Also the uptake rate of dextran particles by spleen mononuclear cells was genotype-independent (see online supplementary figure S6B). Together, although we expected Nlrp3-deficiency or Asc-deficiency to reduce caspase-1/ IL-1 $\beta$-dependent inflammation in $\mathrm{B} 6^{l p r}$ mice, lack of NLRP3 and
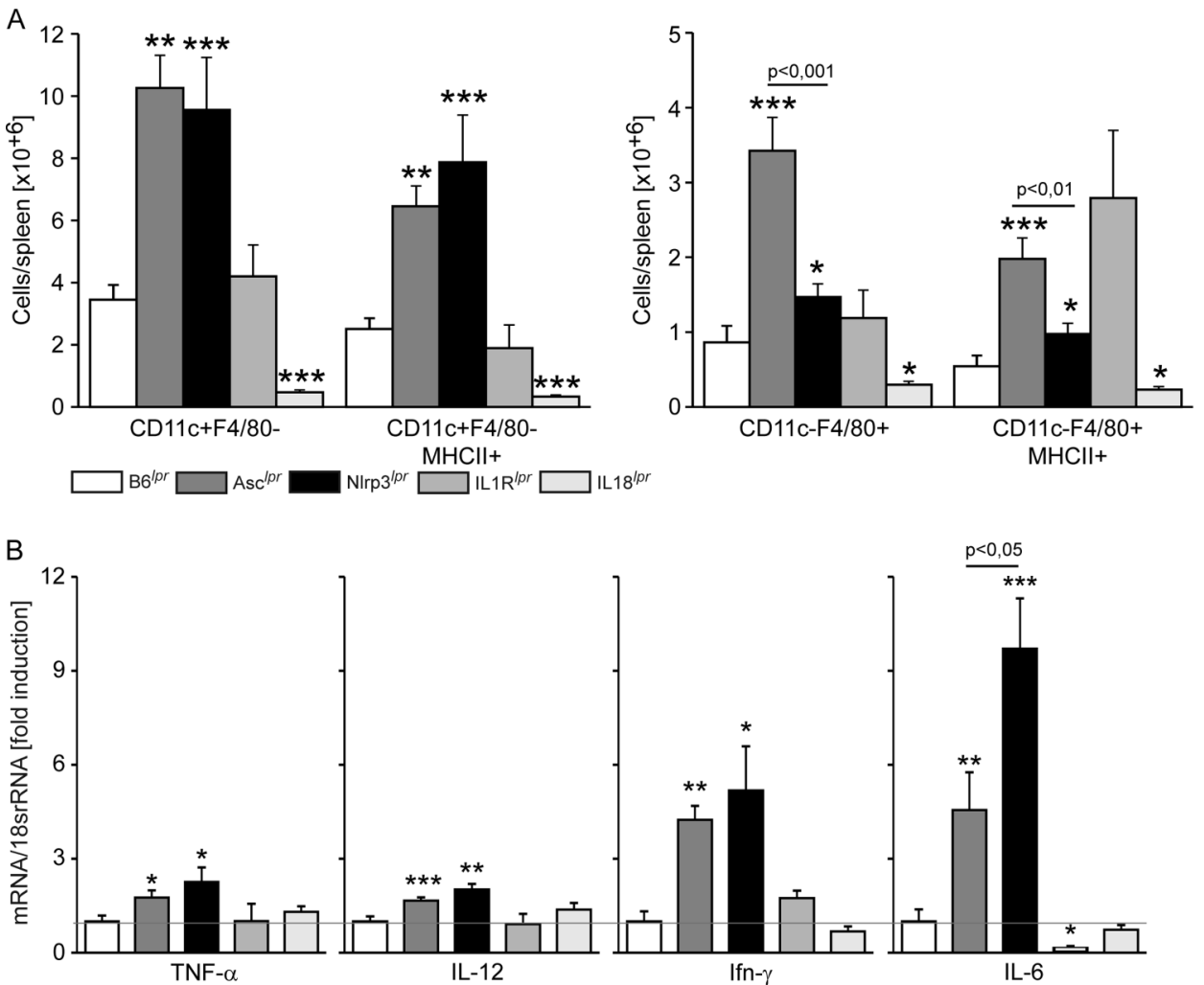

C
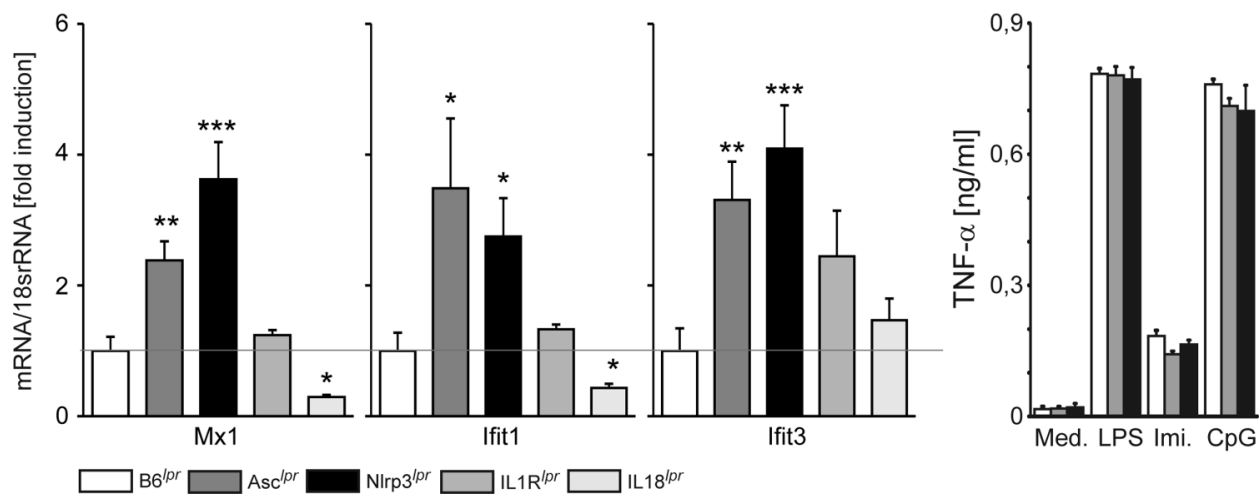

Figure 3 Apoptosis-associated speck-like protein containing a caspase recruitment domain (ASC), NACHT, LRR and PYD domains-containing protein (NLRP3) and myeloid cell activation. (A) The total number of F4/80-/CD11c dendritic cells and CD11c-/F4/80 macrophages and their activation in spleens was quantified by flow cytometry in all investigated genotypes of $B 6^{\text {Ipr }}$ mice as described in methods. Data represent means \pm SEM from at least 10 mice in each group. ${ }^{*} p<0.05 ;{ }^{* *} p<0.01 ;{ }^{* *} p<0.001$ versus $B 6^{\text {Ipr }}$ mice. (B) RNA was isolated from spleens and mRNA levels in spleen were analysed for NF- $\kappa B$ genes expression, proinflammatory genes and type I interferon dependent genes. Expression levels were quantified by real-time PCR and presented as fold induction to controls. Data are shown as means of the ratio of the specific mRNA versus that of $18 \mathrm{~S} r \mathrm{RNA},{ }^{*} \mathrm{p}<0.05 ;{ }^{* *} \mathrm{p}<0.01 ;{ }^{* *} \mathrm{p}<0.001$. (C) Spleen-derived dendritic cells were stimulated with lipopolysaccharide (LPS), imiquimod (Imi) and $\mathrm{CpG}$ as described in methods. Levels of tumour necrosis factor (TNF)- $\alpha$ were determined in supernatants. Data represent means $\pm S E M$. 
ASC (but not of IL-1R or IL-18) was rather associated with increased antigen-presenting cell activation and expression of proinflammatory mediators.

\section{NLRP3 and ASC suppress the expansion of lymphocytes in $B 6^{\text {Ipr }}$ mice}

How does the activation of antigen-presenting cells in Nlrp3-deficient and Asc-deficient $\mathrm{B} 6^{l p r}$ mice affect lymphocyte subsets? CD4 and CD8 T cells as well as CD3CD4/CD8 double negative $\mathrm{T}$ cells, a cell population abnormally expanded in SLE and thought to contribute SLE activity in $\mathrm{B} 6^{l p r}$ mice, ${ }^{46}{ }^{47}$ were all increased and more activated in Nlrp3-deficient and Asc-deficient $\mathrm{B} 6^{l p r}$ mice, as indicated by the activation markers CD69 and CD44 (figure 4A,B,D). CD4/CD25/FoxP3 + 'regulatory' $\mathrm{T}$ cells were significantly increased only in $\mathrm{B} 6{ }^{l p r}$ Asc-/mice (figure 4C). However, Nlrp3-deficiency and Asc-deficiency did not at all affect the capacity of Treg cells to suppress $T$ cell proliferation; further the TGF- $\beta$-induced differentiation of Tregs from CD4 $\mathrm{T}$ cells was not impaired (figure 4E,F). Nlrp3-deficiency and Asc-deficiency also increased the numbers of naïve B cells, marginal zone B cells, follicular B cells, B1 cells with increased surface expression of the activation marker MHC-II and CD19CD69 B cells (figure 5A,B). This was associated with increased mRNA expression of Bcl6, while other factors that drive the proliferation and survival of $\mathrm{B}$ cells and plasma cells were not much affected (figure 5B). Also in vitro activation of TLR4, TLR7 and TLR9 in CD19 B cells was genotype-independent (not shown). In fact, CD138 plasma cells were not significantly expanded in both mutant mouse strains (figure 5C). In contrast, lack of IL-1R or IL-18 did not significantly increase these lymphocyte counts. $I l-18$-deficiency rather reduced them. When analysing lymphocyte data in percentage of all splenocytes no genotype-related differences were seen, which implies unspecific lymphoproliferation. Finally, we phenotyped lymphocyte precursors in bone marrow and thymus of Nlrp3-deficient and Asc-deficient $\mathrm{B} 6^{l p r}$ mice and $\mathrm{B} 6^{l p r}$ controls. There was no consistent alteration of lymphocyte maturation that could explain the observed phenotype in adult mice (data not shown). Together, Nlrp3-deficiency or Asc-deficiency (but not IL-1R or IL-18) deficiency is associated with abnormal expansion of $\mathrm{T}$ cells (including CD4/CD8 double positive $\mathrm{T}$ cells) and on several B cell subsets (but not plasma cells) in $\mathrm{B}^{\mathrm{lpr}}$ mice. Also the numbers of bone marrow plasma cells were not affected by the genotypes (see online supplementary figure S6C). This implies that NLRP3 and ASC have an immunosuppressive effect on $\mathrm{T}$ cells and $\mathrm{B}$ cells in $\mathrm{B} 6^{p r}$ mice that is independent from their capacity to trigger IL-1 and IL-18 secretion.

\section{Lack of NLRP3 or ASC has little effects on systemic inflammation and autoantibody production in $\mathrm{B}^{\mathbf{p r}}$ mice}

As Nlrp3-deficiency and Asc-deficiency had not significantly affected plasma cell counts in $\mathrm{B} 6^{l p r}$ mice, we questioned whether enhanced lymphoproliferation and $\mathrm{T}$ cell and $\mathrm{B}$ cell activation at all translated into more IgG and autoantibody production or systemic inflammation. Plasma levels of multiple proinflammatory and immunoregulatory cytokines were largely genotype-independent except for a significant increase of IL-12p40 and IL-23 in Nlrp3-deficient $\mathrm{B} 6^{l p r}$ mice (figure 5E). Interferon- $\alpha / \beta$, IL-1 $\beta$ and IL-10 plasma levels were undetectable in all genotypes. Also plasma IgG levels were comparable in all strains (figure 5D). Among the lupus autoantibodies only rheumatoid factor and anti-dsDNA IgG were significantly increased in $\mathrm{B}^{l p r} \mathrm{Nlpr3-/-}$ mice (figure 5D), the latter confirmed by Crithidia luciliae assay (not shown). Despite some trends of higher antibody levels in individual mice of the mutant strains there was no statistically significant difference among the genotypes for the other lupus autoantibodies tested (figure 5D). Thus, the suppressive effect of NLRP3 and ASC on $\mathrm{T}$ cells and $\mathrm{B}$ cells in $\mathrm{B} 6^{l p r}$ mice does not much affect plasma cytokine and antibody levels.

\section{NLRP3 and ASC regulate TGF- $\beta$ signalling in $B 6^{\text {Ipr }}$ mice}

What could be the reason for this unexpected aggravation of nephritis-related autoimmunity of the Nlrp3-deficient and Asc-deficient $\mathrm{B} 6^{l p r}$ mice? Among the known IL-1-independent and IL-18-independent effects of NLRP3 and ASC, ${ }^{45-50}$ only their role in TGF- $\beta$ R signalling (until now documented for TGF- $\beta$-induced epithelial-mesenchymal transition in kidney epithelial cells ${ }^{50}$ ) has the potential to explain NLRP3-related and ASC-related immunosuppression. In fact, of Nlrp3-deficient or Asc-deficient $\mathrm{B}^{l p r}$ mice revealed less Smad-2 phosphorylation on western blots of spleen isolates (figure 6A), which was associated with a reduction in TGF- $\beta 1$-induced nuclear translocation of Smad 2/3 in Asc-deficient or Nlrp3-deficient bone marrow dendritic cells as compared with wild type dendritic cells (figure 6B). In addition, ASC and NLRP3 were needed in dendritic cells for full TGF- $\beta 1$-mediated suppression of IL- 6 production upon LPS stimulation (figure 6C). As a further proof of the concept that ASC and NLRP3 are needed for TGF-R signalling, spleen mRNA profiling by PCR array revealed that lack of ASC or NLRP3 suppressed the expression of most TGF- $\beta$ target genes in $\mathrm{B} 6^{l p r}$ mice (figure $6 \mathrm{D}$ ). We selected the most regulated genes and validated their lower spleen mRNA expression levels in comparison with $\mathrm{B} 6^{l p r}$ mice by RT-PCR (figure 6D). Spleen TGF-R chain mRNA expression levels and serum TGF- $\beta$ levels excluded an upstream defect of TGF-R signalling, in fact, TGF $\beta R 1$ and TGF $\beta R 2$ chains were rather induced than suppressed in Nlrp3-deficient or Asc-deficient $\mathrm{B} 6^{l p r}$ mice (figure $6 \mathrm{E}$, F). We conclude that ASC and NLRP3 are needed for TGF- $\beta 1$-mediated Smad-2/3 phosphorylation in dendritic cells and subsequent TGF- $\beta$ target gene expression in spleens of $\mathrm{B} 6^{l p r}$ mice. Hence, lack of ASC or NLRP3 (but not of IL-1R or IL-18) impairs the immunoregulatory effect of TGF- $\beta 1$ signalling in $6^{l p r}$ mice.

\section{DISCUSSION}

We had hypothesised that lack of NLRP3 or ASC would attenuate systemic autoimmunity and lupus-like nephritis in $\mathrm{B}^{l p r}$ mice, mainly because canonical NLRP3 inflammasome activation via caspase-1, IL-1 $\beta$ and IL-18 should elicit proinflammatory effects. ${ }^{8} 1119$ However, our data disprove this concept and rather document that NLRP3 and ASC limit the expansion and activation of antigen-presenting cells and of T cells and $\mathrm{B}$ cells and, subsequently, autoimmune tissue inflammation in $\mathrm{B} 6^{l p r}$ mice. Interestingly, lupus autoantibody production and immune complex disease were hardly affected by lack of NLRP3 or ASC, implying an immunoregulatory role of NLRP3 and ASC mainly on cellular immunity. Obviously, the NLRP3 inflammasome has previously unknown immunoregulatory effects in the context of experimental SLE. Until now, aggravation of disease in Nlrp3-deficient mice has rarely been reported. For example, NLRP3 suppresses antitumor immunity and age-related macula degeneration. $^{5152}$

The NLRP3 inflammasome contributes to host defence and to autoinflammatory disorders consistently via the proinflammatory effects of caspase- 1 activation in mononuclear phagocytes. The proinflammatory effects of caspase- 1 are threefold: via pyroptosis, a programmed form of inflammatory cell death ${ }^{11}$ and via secretion 


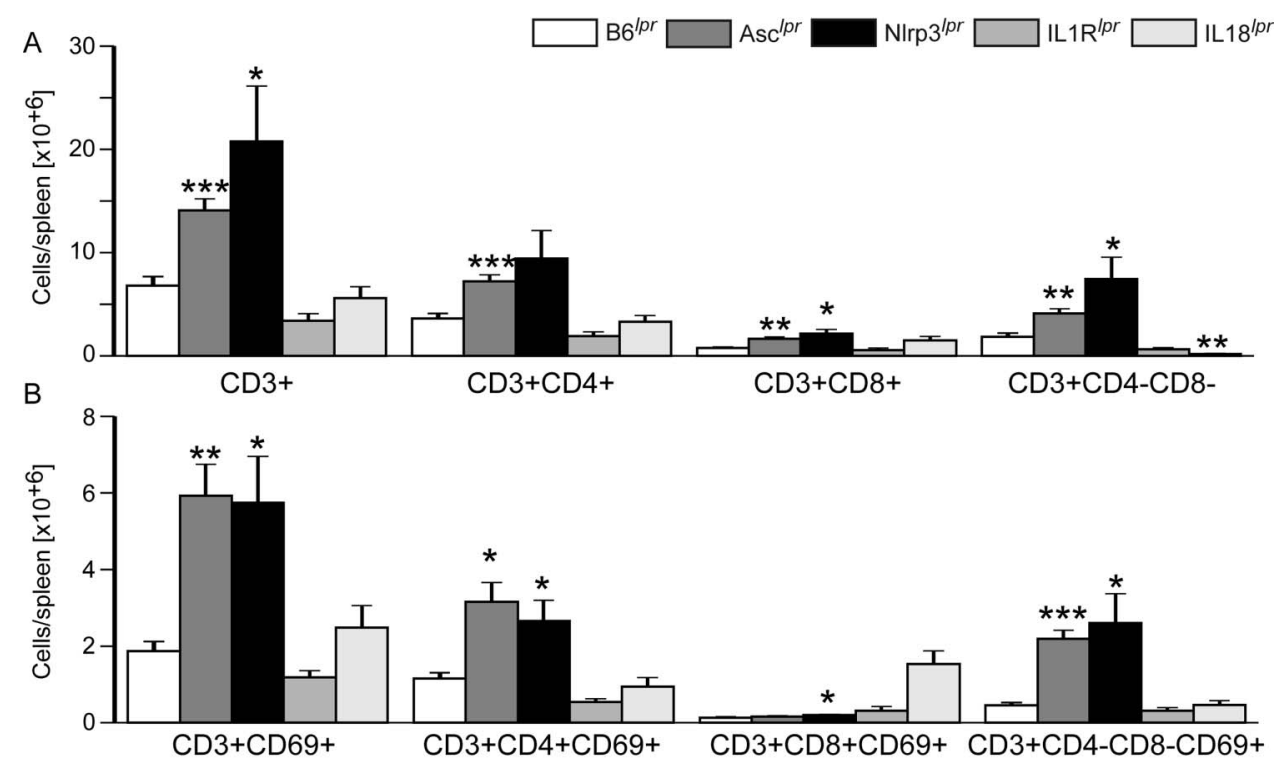

C

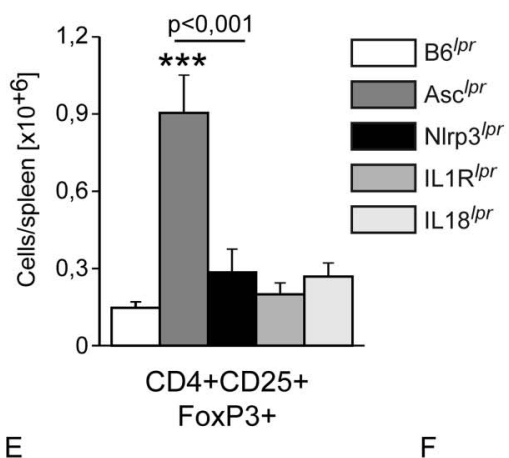

$\mathrm{E}$

$\mathrm{F}$

D
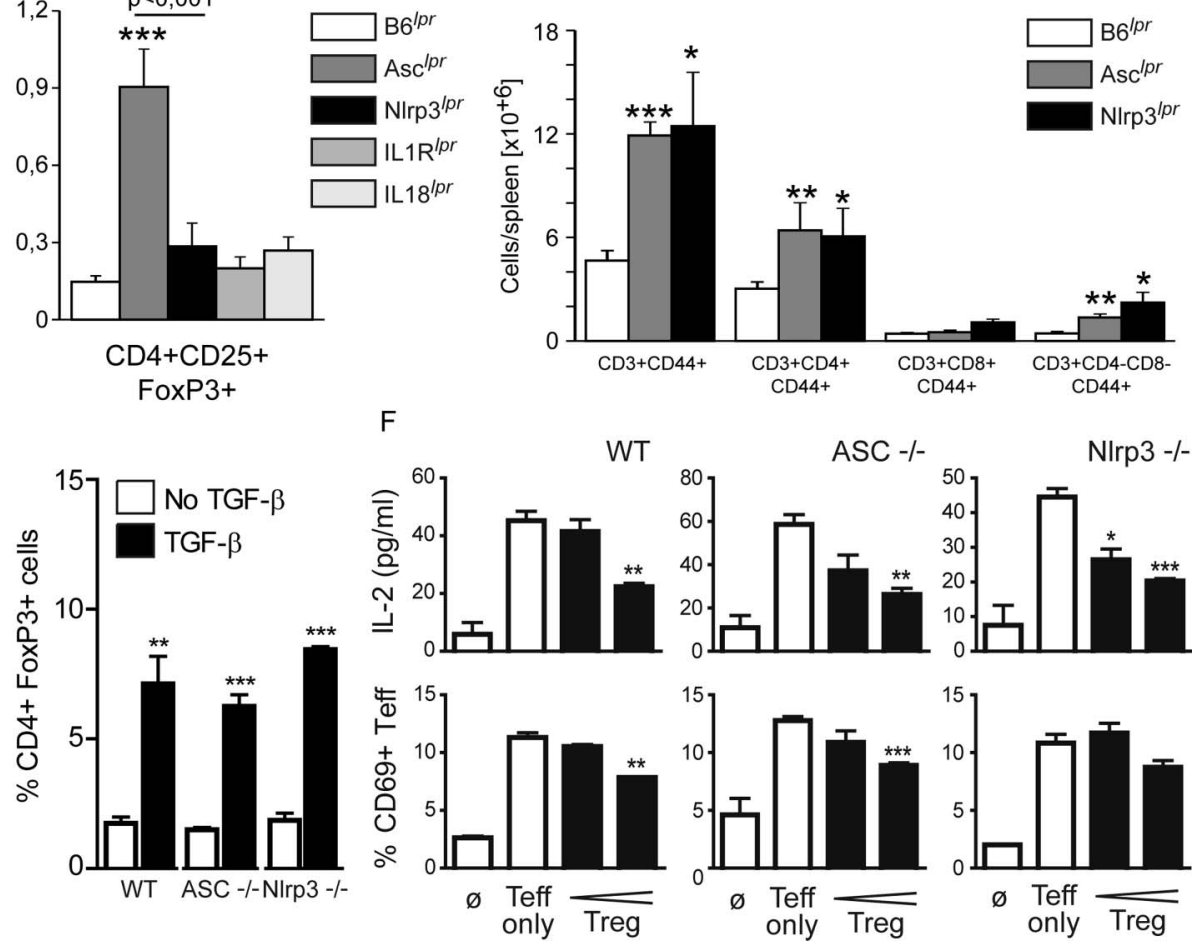

WT

ASC -/-

NIrp3 -/-

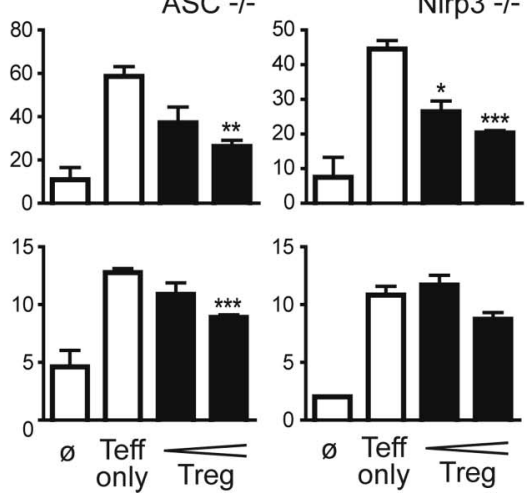

Figure 4 Characterisation of $T$ cell subsets and regulatory $T$ cell function. (A-D) Flow cytometry was used to determine the total number of

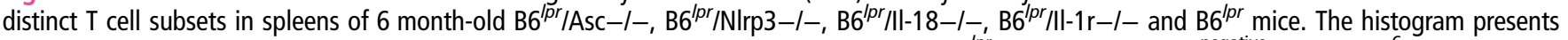
means \pm SEM of at least 15 mice in each group. ${ }^{*} p<0.05,{ }^{* *} p<0.01,{ }^{* *} p<0.001$ versus $B 6^{\text {pr }}$ mice. (E) CD4CD25 ${ }^{\text {negative }}$ cells $\left(1 \times 10^{6}\right)$ that were isolated from the spleen of the indicated mice were stimulated with anti-CD3-CD28 beads and tumour growth factor (TGF)- $\beta$ in the presence of interleukin (IL)-2. The percentage of CD4FoxP3 cells in the culture was determined on day 3 by flow cytometry. Conditions without TGF- $\beta$ were treated with beads and IL-2 only. Error bars indicate SEM of $n=3$, significance was calculated in comparison with cultures with beads alone: ${ }^{* *} p<0.01 ;{ }^{* *} p<0.001$. (F) CD4CD25 and CD4CD25 ${ }^{\text {negative }}$ cells were isolated from the spleen of the indicated mice. For analysis of regulatory $T$ cell function, CD4CD25 ${ }^{\text {negative }}$ were stimulated with anti-CD3-CD28 beads in the presence of increasing numbers of CD4CD25 cells. After 3 days, IL-2 secretion and expression of CD69 and CD44 by the T cells were determined. $\varnothing$, T effector cells without stimulation, Teff only, conditions without CD4CD25 cells, significance was calculated in comparison with cultures with Teff only. Error bars indicate SEM of $n=3$, significance was calculated in comparison with cultures with beads alone: ${ }^{*} \mathrm{p}<0.05 ;{ }^{* *} \mathrm{p}<0.01 ;{ }^{* * *} \mathrm{p}<0.001$.

of IL-1 $\beta$ and IL-18, which trigger inflammation via IL-1R and IL-18R signalling systemically and in many tissues. ${ }^{9} 10$ As expected, Nlrp3-deficiency and Asc-deficiency (but not $I l-1 r$-deficiency or $I l-18$-deficiency) reduced caspase- 1 activation in $\mathrm{B} 6^{l p r}$ mice, hence, the associated activation of myeloid antigen- presenting cells and the expression of numerous proinflammatory mediators are inconsistent with what has been demonstrated in experimental infection or sterile inflammation. ${ }^{11} 19-2331-33$ So by which mechanisms could Nlrp3-deficiency and Asc-deficiency drive lymphoproliferation, immune cell activation and lupus 

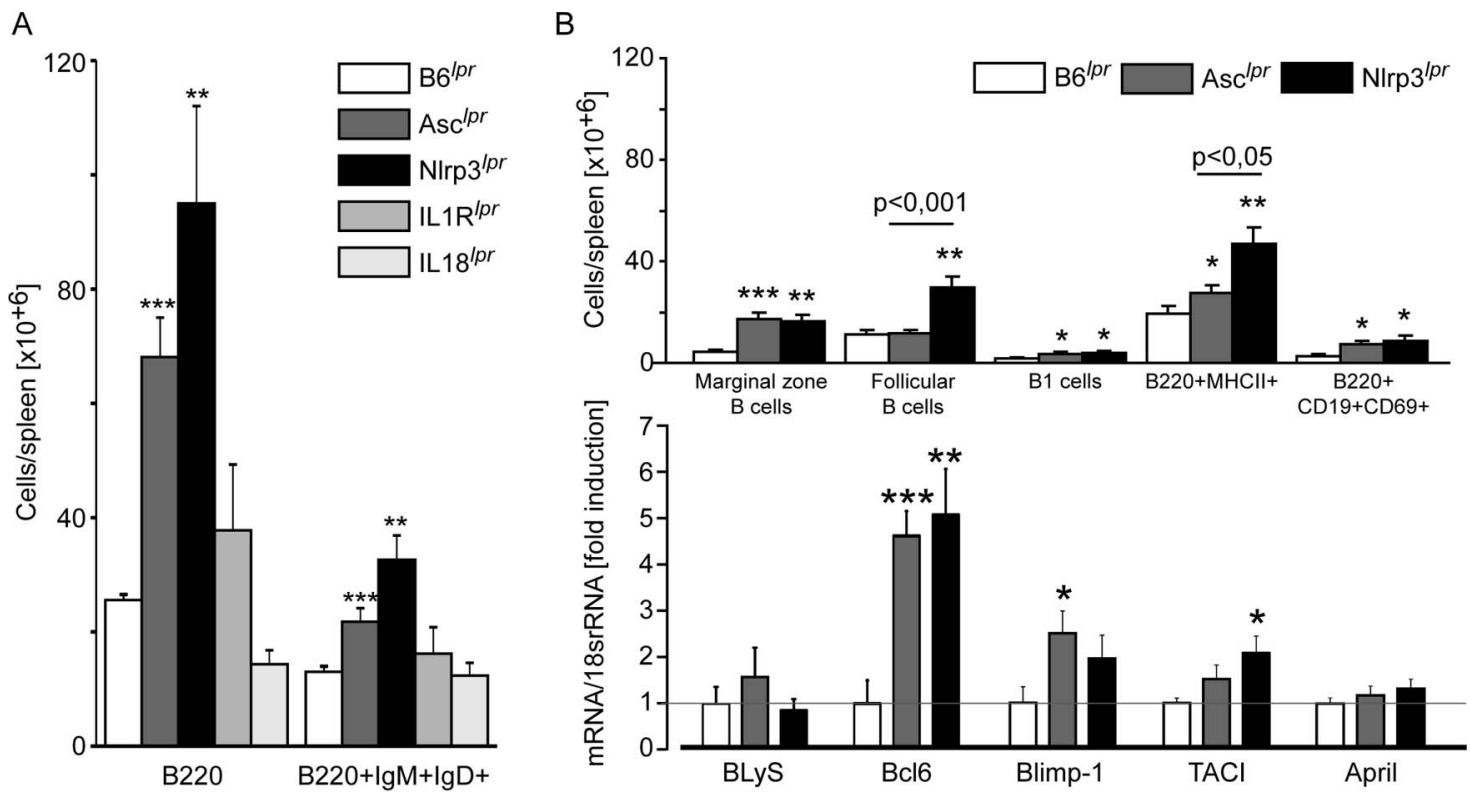

C
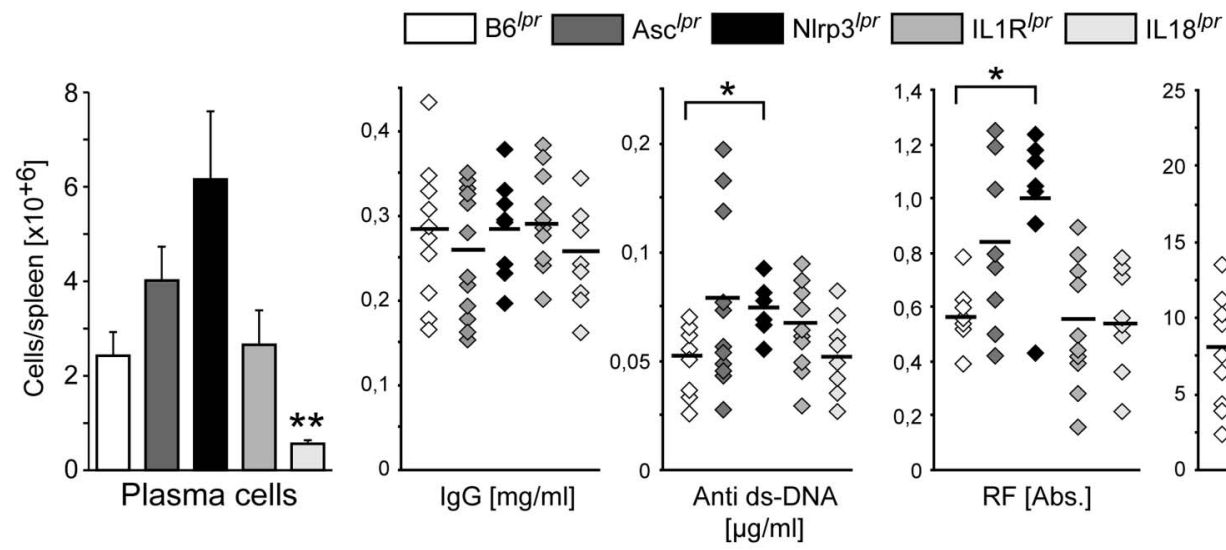

E

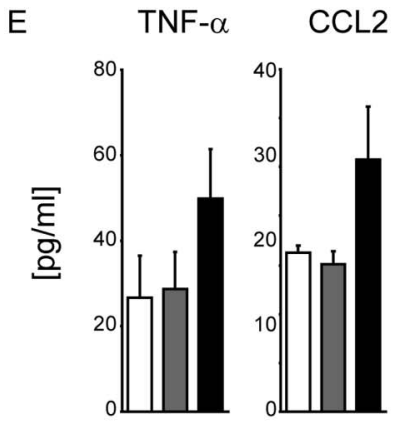

IL-4

IL-12 p40

IL-17
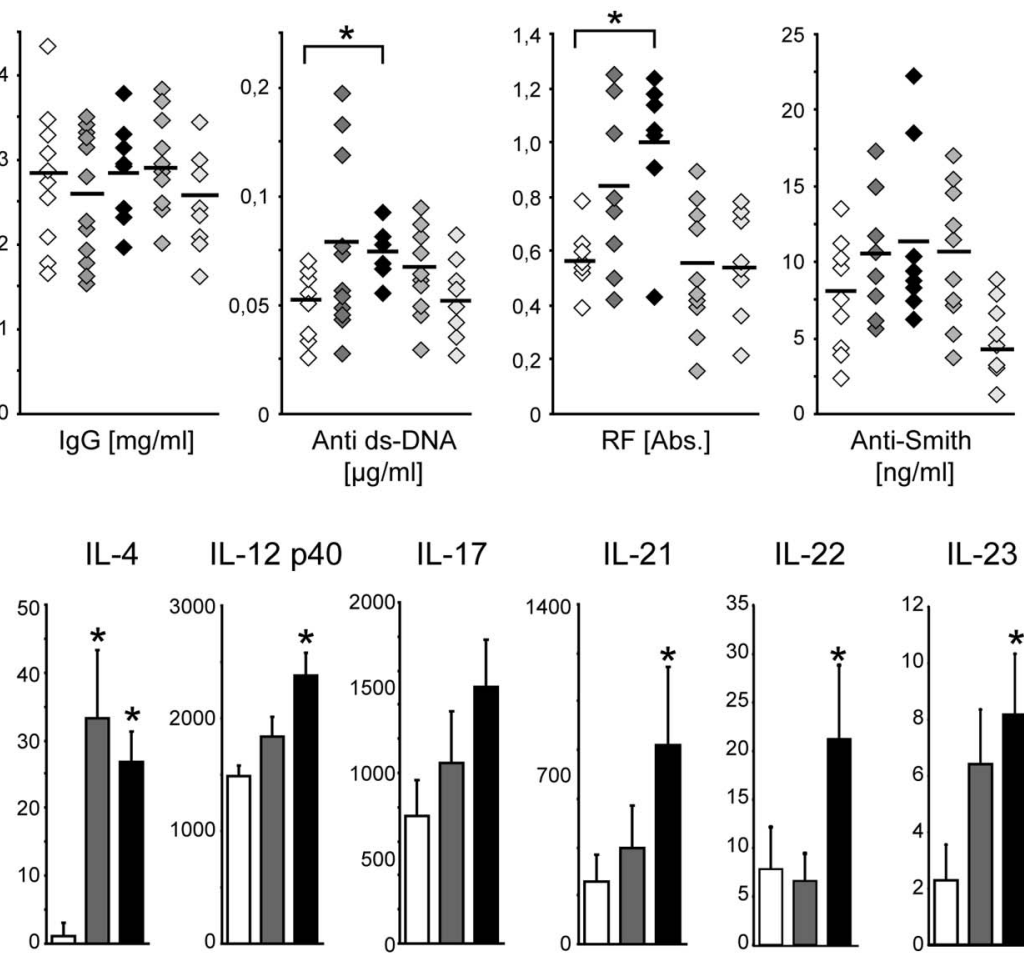

IL-21

IL-22

IL-23
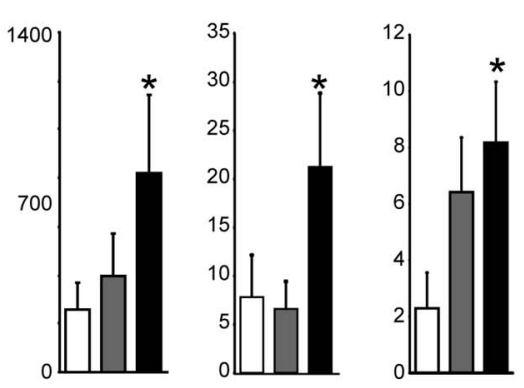

$\mathrm{B6}^{\mathrm{lpr}} \square \mathrm{Asc}^{\mathrm{pr}} \square \mathrm{Nlrp3}^{\mathrm{pr}}$

Figure 5 B cell subsets and antibody production in B6 ${ }^{/ p r}$ mice. (A and C) The total number of spleen B220 cells, B220/lgM/lgD mature B cells and

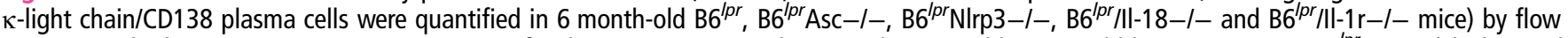
cytometry. The histogram presents means $\pm S E M$ of at least 15 mice in each group; ${ }^{*} p<0.05,{ }^{* *} p<0.01,{ }^{* * *} p<0.001$ versus $B 6^{\text {pr }}$ mice. (B) The total

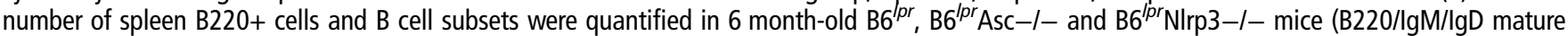
B cells; B220 CD21high/CD23low marginal zone B cells; B220 CD21low/CD23high follicular B cells; B1-cells and B220/CD19/CD69 B cells) by flow cytometry. The histogram presents means $\pm S E M$ of at least 15 mice in each group; ${ }^{*} p<0.05,{ }^{* *} p<0.01,{ }^{* * *} p<0.001$ versus $B 6^{\text {lpr }}$ mice. (B) mRNA levels in spleen were analysed for B cell survival and stimulatory factors. Expression levels were quantified by real-time PCR and presented as fold induction to controls. Data are shown as means of the ratio of the specific mRNA versus that of $18 \mathrm{~S}$ rRNA, ${ }^{*} p<0.05 ;{ }^{* *} p<0.01 ;{ }^{* * *} p<0.001$ versus $\mathrm{B}^{\text {lpr }}$ mice. (D) Mice from all groups were bled at month 6 to determine serum levels of immunoglobin $\mathrm{G}$ (IgG) and ds-DNA autoantibody, autoantibodies against Smith antigen or rheumatoid factor (RF) by ELISA. Data show individual mice from each group. The mean is indicated by a bar; ${ }^{*} p<0.05$ versus $B 6^{l p r}$ mice. (E) B6lpr, B6lprAsc-l- and B6lprNlrp3-1- mice were bled at month 6 to determine serum levels of interleukin (IL)-4, IL-12, IL-17, IL-21, IL-22, IL-23, monocyte chemoattractant protein-1 and tumour necrosis factor (TNF)- $\alpha$. Same grey scale for groups was used as for $6 \mathrm{D}$. Data represent means \pm SEM from at least eight mice in each group. ${ }^{*} p<0.05$. 
A

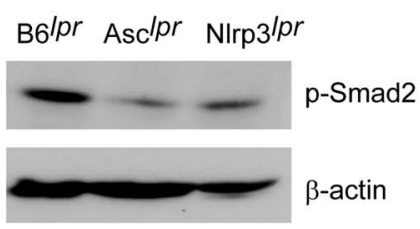

B

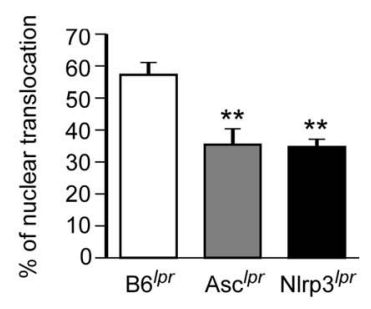

D

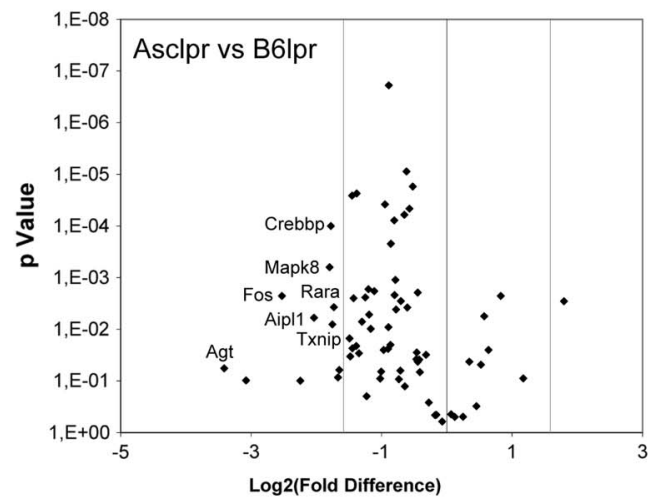

C
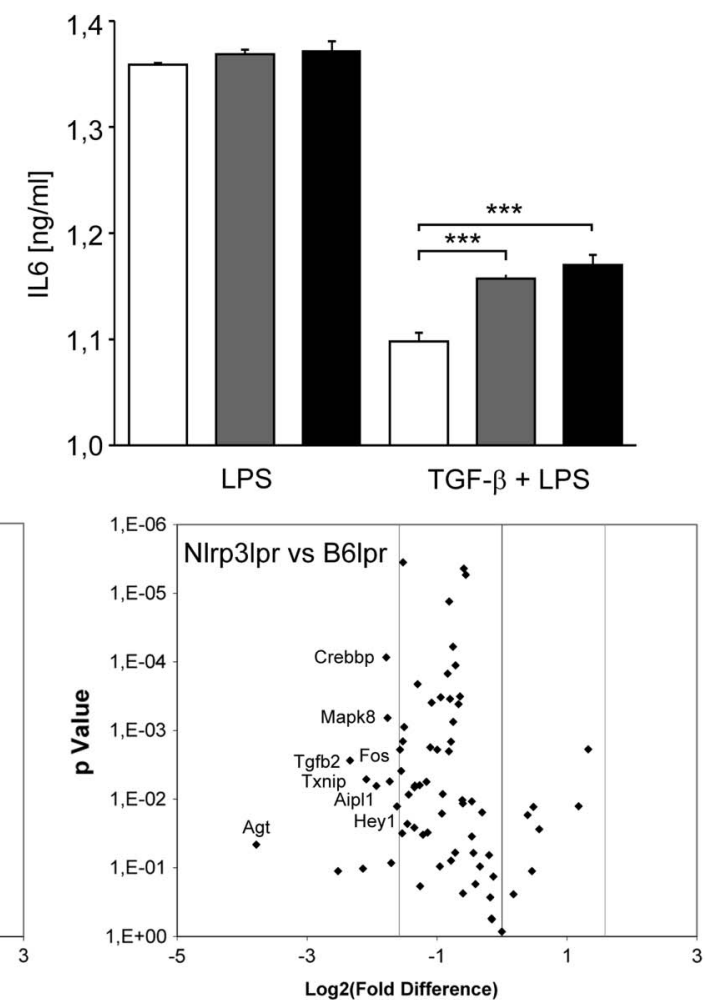

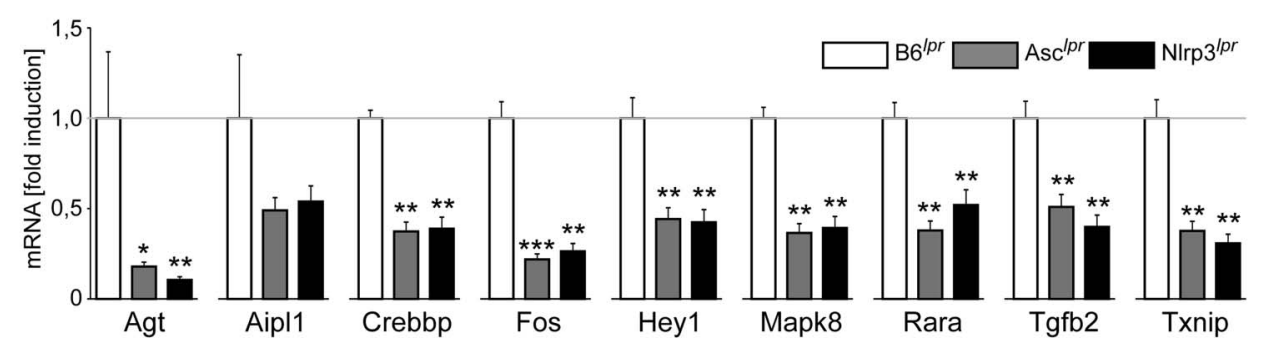

E

$\mathrm{F}$
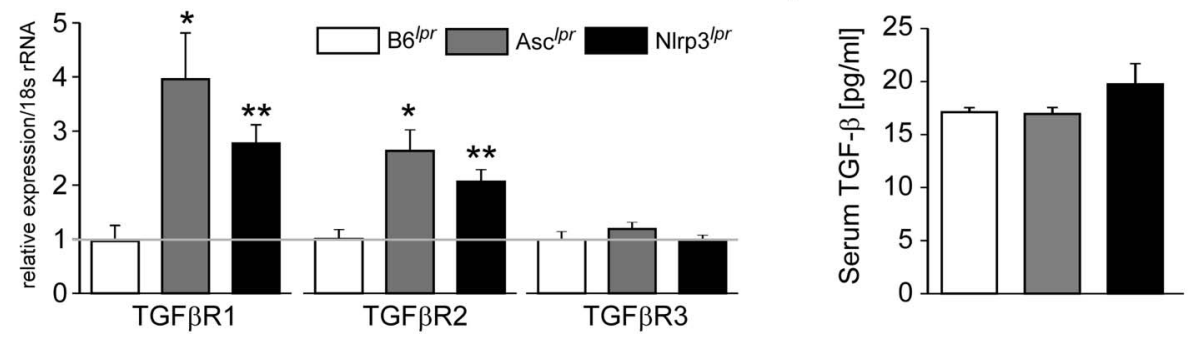

Figure 6 Lack of apoptosis-associated speck-like protein containing a caspase recruitment domain (ASC) and NACHT, LRR and PYD domains-containing protein (NLRP3) and tumour growth factor (TGF)- $\beta$ signalling in $\mathrm{B} 6^{\text {/pr }}$ mice. (A) Western blot analysis shows Smad2 phosphorylation and represents one of three independent experiments. (B) Smad2/3 translocation to the nucleus was quantified by signal intensity. (C) Bone marrow-derived dendritic cells were stimulated with lipopolysaccharide (LPS) alone or with LPS and TGF- $\beta$. Levels of interleukin (IL)- 6 were determined in supernatants. Data represent means \pm SEM; ${ }^{* * *} p<0.001$. (D) mRNA levels in spleen were analysed for TGF- $\beta$-dependent signalling by Qiagen $\mathrm{RT}^{2} \mathrm{PCR}$ profiling array. Results are presented as volcano plots. Expression levels of significantly different expressed genes were quantified by real-time PCR and presented as fold induction to controls. Data are shown as means of the ratio of the specific mRNA versus average of five different housekeeping genes as indicated in the Materials and Methods section, ${ }^{*} p<0.05 ;{ }^{* *} p<0.01 ;{ }^{* * *} p<0.001$. (E) RNA was isolated from B6 $6^{\text {pr }}$ / Asc $-1-, B 6^{l p r} / \mathrm{Nl} / \mathrm{rp3}-1-$ and $\mathrm{B} 6^{l p r}$ mice for real-time PCR analysis. Data are expressed as means of the ratio of the specific mRNA versus that of $18 \mathrm{~S}$ $\mathrm{rRNA} \pm \mathrm{SEM}$ and presented as fold induction to $\mathrm{B} 6^{\mathrm{lpr}}$ gene expression level; ${ }^{*} \mathrm{p}<0.05 ;{ }^{*} \mathrm{p}<0.01$; versus $\mathrm{B} 6^{\mathrm{pr}}$ mice. (F) Mice from all groups were bled at month 6 to determine serum levels of TGF- $\beta$ by ELISA. Data show means \pm SEM from at least eight mice in each group.

nephritis in SLE-like autoimmunity in an IL-1R-independent and IL-18-independent manner?

Our data point towards impaired TGF- $\beta$ R signalling, a process that is known to control autoimmunity because TGF- $\beta$ is an important negative regulator of the immune system. ${ }^{53}$ TGF- $\beta$ is produced by leucocytes of all lineages to control the differentiation, proliferation and activation in autocrine and paracrine manners. As such, TGF- $\beta$ is a guardian factor of 
immune tolerance and T cell-mediated autoimmunity. ${ }^{54} 55$ For example, mice deficient in either TGF- $\beta 1$ or TGF-R display spontaneous lethal autoimmunity. ${ }^{56-58}$ Our model did not display lethality, which is consistent with our in vitro data that suggest a moderate modulatory effect of Nlrp3-deficiency or Asc-deficiency rather than a complete blockade of TGF- $\beta$ signalling. TGF- $\beta 1$-mediated immunosuppression mostly affects dendritic cells, macrophages and T cells, ${ }^{55} 59$ which is consistent with our own observations in Nlrp3-deficient and Asc-deficient B $6^{l p r}$ mice. For example, autoimmunity of Tgf- $\beta 1$-deficient mice depends on self-antigen presentation via enhanced MHC class II expression, ${ }^{60}{ }^{61}$ a phenomenon also observed by us in Nlrp3-deficient and Asc-deficient B $6^{l p r}$ mice. In fact, dendritic cell-specific deletion of TGF- $\beta$ RII is sufficient to induce spontaneous multiorgan autoimmunity, ${ }^{62}$ which documents that TGF- $\beta \mathrm{R}$ signalling in dendritic cells is sufficient to control autoimmunity and does not necessarily require TGF- $\beta$ R-mediated immunosuppression from regulatory T cells. ${ }^{55} 57$ This is important as we could not detect any effect of Nlrp3-deficiency and Asc-deficiency on regulatory $\mathrm{T}$ cell control of $\mathrm{T}$ cell proliferation.

In contrast to the prominent effect of Nlrp3-deficiency and Asc-deficiency on cellular immunity, spleen plasma cell counts and immunoglobulin or autoantibody production were affected to the same extent inB6 $6^{l p r}$ mice, except for somewhat higher dsDNA antibody and rheumatoid factor levels in Nlrp3-deficient mice. Therefore, immune complex disease, as determined by glomerular immune complex deposits, was genotype-independent. Immune complex-deposition is the diagnostic hallmark and a sine qua non for lupus nephritis, ${ }^{39} 63$ but disease activity is also determined by infiltrating effector $\mathrm{T}$ cells and macrophages. ${ }^{64} 65$ The same applies to autoimmune lung disease inB $6^{l p r}$ mice, which is rather determined by de novo tertiary lymphoid tissue formation in the peribronchial compartment, than by immune complex disease. ${ }^{36}$ Therefore, lung disease and nephritis could still be markedly aggravated in Nlrp3-deficient and Asc-deficient $\mathrm{B} 6^{l p r}$ mice, despite negligible effects on humoral immunity.

A similar contradictory phenotype had been found for TLR9-deficient $\mathrm{B} 6^{l p r}$ mice, ${ }^{66}$ which was confirmed in several other lupus nephritis mouse models. ${ }^{356768}$ Before, numerous in vitro and in vivo studies had documented the proinflammatory and B cell mitogenic effect of TLR9 signalling, ${ }^{69-72}$ especially when stimulated with self-DNA from immune complexes. ${ }^{37}$ 73-75 Later, it was discovered that this unexpected phenotype of TLR9-mutant mice related to a TLR7 inhibitory effect during the early phase of SLE, ${ }^{76} 77$ while TLR9 blockade in the subsequent progression phase of SLE attenuated autoantibody production and inflammatory organ manifestations. ${ }^{78-81}$ Obviously, immunostimulatory pattern recognition receptors can elicit unexpected outcomes in autoimmunity when they specifically modulate immune tolerance and adaptive immunity in lupus. There were very few phenotypical differences between Nlrp3-deficient and Asc-deficient B6 ${ }^{l p r}$ mice that may indicate specific immunoregulatory functions of ASC and NLRP3 independent from each other.

In summary, in $\mathrm{B}^{l p r}$ mice NLRP3 and ASC, the two components of the NLRP3 inflammasome, are needed to avoid excessive lymphoproliferative syndrome and autoimmune tissue injury, but this effect is independent of their canonical role in IL-1 and IL-18 secretion. This unexpected non-canonical function of NLRP3 and ASC seems to relate to their role in TGF- $\beta$ R signalling, for example, in $S \operatorname{mad} 2 / 3$ phosphorylation. TGF- $\beta$ target gene expression is needed to regulate the activation and expansion of myeloid antigen-presenting cells as well as most T cell and B cell subsets. Together we conclude, the NLRP3 inflammasome suppresses cellular autoimmunity in systemic lupus nephritis of $\mathrm{B} 6^{l p r}$ mice, which defines another biological function of NLRP3 and ASC beyond pathogen recognition. ${ }^{82}$

Acknowledgements The authors thank Ewa Radomska, Dan Draganovic and Jana Mandelbaum for the expert technical assistance.

Contributors ML, GL, OPK, MOOG, NS, MND, RG, MWMW, DA, HES and H-JA performed experiments, analysed data and approved the final version of the manuscript. ML, GL and H-JA designed the study and wrote the manuscript.

Funding The work was supported by grants from the Deutsche Forschungsgemeinschaft (AN372/9-2, LE2621/3-1 and GRK 1202).

Competing interests Parts of this work were performed as medical thesis projects by GL at the Medical Faculty of the University of Munich.

Ethics approval All animal experiments were approved by the Local Governmental Authorities.

Provenance and peer review Not commissioned; externally peer reviewed.

Data sharing statement All data are mentioned or displayed in the manuscript.

\section{REFERENCES}

1 Rahman A, Isenberg DA. Systemic lupus erythematosus. N Engl J Med 2008;358:929-39.

2 Munoz LE, Lauber $K$, Schiller $M$, et al. The role of defective clearance of apoptotic cells in systemic autoimmunity. Nat Rev Rheumatol 2010;6:280-9.

3 Liu Z, Davidson A. Taming lupus-a new understanding of pathogenesis is leading to clinical advances. Nat Med 2012;18:871-82.

4 Marshak-Rothstein A, Rifkin IR. Immunologically active autoantigens: the role of toll-like receptors in the development of chronic inflammatory disease. Annu Rev Immunol 2007;25:419-41.

5 Anders HJ. Pseudoviral immunity - a novel concept for lupus. Trends Mol Med 2009;15:553-61.

6 Kulkarni OP, Anders HJ. Lupus nephritis. How latest insights into its pathogenesis promote novel therapies. Curr Opin Rheumatol 2012;24:457-65.

7 Allam R, Lichtnekert J, Moll AG, et al. Viral RNA and DNA trigger common antiviral responses in mesangial cells. J Am Soc Nephrol 2009;20:1986-96.

8 Schroder K, Tschopp J. The inflammasomes. Cell 2010;140:821-32.

9 Dinarello CA. Interleukin-18 and the pathogenesis of inflammatory diseases. Semin Nephrol 2007;27:98-114.

10 Dinarello CA. Interleukin-1 beta and the autoinflammatory diseases. N Eng/ J Med 2009;360:2467-70.

11 Bergsbaken T, Fink SL, Cookson BT. Pyroptosis: host cell death and inflammation. Nat Rev Microbiol 2009;7:99-109.

12 Dostert C, Petrilli V, Van Bruggen $R$, et al. Innate immune activation through Nalp3 inflammasome sensing of asbestos and silica. Science 2008;320:674-7.

13 Duewell P, Kono H, Rayner KJ, et al. NLRP3 inflammasomes are required for atherogenesis and activated by cholesterol crystals. Nature 2010;464:1357-61.

14 Martinon F, Petrilli V, Mayor A, et al. Gout-associated uric acid crystals activate the NALP3 inflammasome. Nature 2006;440:237-41.

15 Mulay SR, Kulkarni OP, Rupanagudi KV, et al. Calcium oxalate crystals induce renal inflammation by NLRP3-mediated IL-1 beta secretion. J Clin Invest 2013;123:236-46.

16 Darisipudi MN, Thomasova D, Mulay SR, et al. Uromodulin triggers IL-1 beta-dependent innate immunity via the NLRP3 inflammasome. J Am Soc Nephrol 2012;23:1783-9.

17 Willingham SB, Bergstralh DT, O'Connor W, et al. Microbial pathogen-induced necrotic cell death mediated by the inflammasome components CIAS1/cryopyrin/ NLRP3 and ASC. Cell Host Microbe 2007;2:147-59.

18 Miao EA, Rajan JV, Aderem A. Caspase-1-induced pyroptotic cell death. Immunol Rev 2011;243:206-14.

19 Shaw PJ, McDermott MF, Kanneganti TD. Inflammasomes and autoimmunity. Trends Mol Med 2011;17:57-64.

20 Besnard AG, Togbe D, Couillin I, et al. Inflammasome-IL-1-Th17 response in allergic lung inflammation. J Mol Cell Biol 2012;4:3-10.

21 Gris D, Ye Z, locca HA, et al. NLRP3 plays a critical role in the development of experimental autoimmune encephalomyelitis by mediating Th1 and Th17 responses. J Immunol 2010;185:974-81.

22 Inoue M, Williams KL, Gunn MD, et al. NLRP3 inflammasome induces chemotactic immune cell migration to the CNS in experimental autoimmune encephalomyelitis. Proc Natl Acad Sci USA 2012;109:10480-5.

23 Brydges SD, Mueller JL, McGeough MD, et al. Inflammasome-mediated disease animal models reveal roles for innate but not adaptive immunity. Immunity 2009;30:875-87 
24 Meng G, Zhang F, Fuss I, et al. A mutation in the Nlrp3 gene causing inflammasome hyperactivation potentiates Th17 cell-dominant immune responses. Immunity 2009;30:860-74.

25 Chang DM. Interleukin-1 and interleukin-1 receptor antagonist in systemic lupus erythematosus. Immunol Invest 1997;26:649-59.

26 Ostendorf B, Iking-Konert C, Kurz K, et al. Preliminary results of safety and efficacy of the interleukin 1 receptor antagonist anakinra in patients with severe lupus arthritis. Ann Rheum Dis 2005:64:630-3.

27 Moosig $F$, Zeuner $R$, Renk $C$, et al. IL-1RA in refractory systemic lupus erythematosus. Lupus 2004;13:605-6.

28 Kiberd BA, Stadnyk AW. Established murine lupus nephritis does not respond to exogenous interleukin-1 receptor antagonist; a role for the endogenous molecule? Immunopharmacology 1995;30:131-7.

29 Doria $\mathrm{A}$, Zen $\mathrm{M}$, Bettio $\mathrm{S}$, et al. Autoinflammation and autoimmunity: bridging the divide. Autoimmun Rev 2012;12:22-30.

30 Favilli F, Anzilotti C, Martinelli L, et al. IL-18 activity in systemic lupus erythematosus. Ann N Y Acad Sci 2009:1173:301-9.

31 Shin MS, Kang Y, Lee N, et al. U1-small nuclear ribonucleoprotein activates the NLRP3 inflammasome in human monocytes. J Immunol 2012;188:4769-75.

32 Shin MS, Kang $\mathrm{Y}$, Lee $\mathrm{N}$, et al. Self double-stranded (ds)DNA induces IL-1 beta production from human monocytes by activating NLRP3 inflammasome in the presence of anti-dsDNA antibodies. J Immunol 2013;190:1407-15.

33 Kahlenberg JM, Carmona-Rivera C, Smith CK, et al. Neutrophil extracellular trap-associated protein activation of the NLRP3 inflammasome is enhanced in lupus macrophages. J Immunol 2013;190:1217-26.

34 Cohen PL, Eisenberg RA. Lpr and gld: single gene models of systemic autoimmunity and lymphoproliferative disease. Annu Rev Immunol 1991;9:243-69.

35 Wu X, Peng SL. Toll-like receptor 9 signaling protects against murine lupus. Arthritis Rheum 2006;54:336-42.

36 Lech M, Rommele C, Kulkarni OP, et al. Lack of the long pentraxin PTX3 promotes autoimmune lung disease but not glomerulonephritis in murine systemic lupus erythematosus. PLoS One 2011;6:e20118.

37 Lech M, Kulkarni OP, Pfeiffer $S$, et al. Tir8/Sigirr prevents murine lupus by suppressing the immunostimulatory effects of lupus autoantigens. J Exp Med 2008:205:1879-88

38 Lech M, Kantner C, Kulkarni OP, et al. Interleukin-1 receptor-associated kinase-M suppresses systemic lupus erythematosus. Ann Rheum Dis 2011;70:2207-17.

39 Lech M, Weidenbusch M, Kulkarni OP, et al. IRF4 deficiency abrogates lupus nephritis despite enhancing systemic cytokine production. J Am Soc Nephrol 2011;22:1443-52.

40 Mariathasan S, Newton K, Monack DM, et al. Differential activation of the inflammasome by caspase-1 adaptors ASC and Ipaf. Nature 2004;430:213-18.

41 Patole PS, Pawar RD, Lichtnekert J, et al. Coactivation of Toll-like receptor-3 and -7 in immune complex glomerulonephritis. J Autoimmun 2007;29:52-9.

42 Allam R, Pawar RD, Kulkarni OP, et al. Viral 5'-triphosphate RNA and non-CpG DNA aggravate autoimmunity and lupus nephritis via distinct TLR-independent immune responses. Eur I Immunol 2008;38:3487-98.

43 Lech M, Susanti HE, Rommele C, et al. Quantitative expression of C-type lectin receptors in humans and mice. Int J Mol Sci 2012;13:10113-31.

44 Allam R, Sayyed SG, Kulkarni OP, et al. Mdm2 promotes systemic lupus erythematosus and lupus nephritis. J Am Soc Nephrol 2011;22:2016-27.

45 Latz E, Xiao TS, Stutz A. Activation and regulation of the inflammasomes. Nat Rev Immunol 2013;13:397-411.

46 Ford MS, Young KJ, Zhang Z, et al. The immune regulatory function of lymphoproliferative double negative T cells in vitro and in vivo. J Exp Med 2002;196:261-7.

47 Hammond DM, Nagarkatti PS, Gote LR, et al. Double-negative T cells from MRL-Ipr/ Ipr mice mediate cytolytic activity when triggered through adhesion molecules and constitutively express perforin gene. J Exp Med 1993;178:2225-30.

48 Shigeoka AA, Mueller JL, Kambo A, et al. An inflammasome-independent role for epithelial-expressed Nlrp3 in renal ischemia-reperfusion injury. I Immunol 2010;185:6277-85.

49 Sokolovska A, Becker CE, Ip WK, et al. Activation of caspase-1 by the NLRP3 inflammasome regulates the NADPH oxidase NOX2 to control phagosome function. Nat Immunol 2013;14:543-53.

50 Wang W, Wang X, Chun J, et al. Inflammasome-independent NLRP3 augments TGF-beta signaling in kidney epithelium. J Immunol 2013;190:1239-49.

51 van Deventer HW, Burgents JE, Wu QP, et al. The inflammasome component NLRP3 impairs antitumor vaccine by enhancing the accumulation of tumor-associated myeloid-derived suppressor cells. Cancer Res 2010;70:10161-9.

52 Doyle SL, Campbell M, Ozaki E, et al. NLRP3 has a protective role in age-related macular degeneration through the induction of IL-18 by drusen components. Nat Med 2012;18:791-8.

53 Letterio JJ, Roberts AB. Regulation of immune responses by TGF-beta. Annu Rev Immunol 1998:16:137-61.
54 Aoki CA, Borchers AT, Li M, et al. Transforming growth factor beta (TGF-beta) and autoimmunity. Autoimmun Rev 2005;4:450-9.

55 Rubtsov YP, Rudensky AY. TGFbeta signalling in control of T-cell-mediated self-reactivity. Nat Rev Immunol 2007;7:443-53.

56 Shull MM, Ormsby I, Kier AB, et al. Targeted disruption of the mouse transforming growth factor-beta 1 gene results in multifocal inflammatory disease. Nature 1992;359:693-9

57 Marie JC, Letterio JJ, Gavin M, et al. TGF-beta1 maintains suppressor function and Foxp3 expression in CD4+CD25+ regulatory T cells. J Exp Med 2005;201:1061-7.

58 Leveen $\mathrm{P}$, Larsson J, Ehinger M, et al. Induced disruption of the transforming growth factor beta type II receptor gene in mice causes a lethal inflammatory disorder that is transplantable. Blood 2002;100:560-8.

59 Bommireddy R, Doetschman T. TGF-beta, T-cell tolerance and anti-CD3 therapy. Trends Mol Med 2004;10:3-9.

60 Letterio JJ, Geiser AG, Kulkarni AB, et al. Autoimmunity associated with TGF-beta1-deficiency in mice is dependent on MHC class II antigen expression. J Clin Invest 1996;98:2109-19.

61 Bommireddy R, Pathak LJ, Martin J, et al. Self-antigen recognition by TGF beta1-deficient $\mathrm{T}$ cells causes their activation and systemic inflammation. Lab Invest 2006;86:1008-19.

62 Ramalingam $\mathrm{R}$, Larmonier $\mathrm{CB}$, Thurston RD, et al. Dendritic cell-specific disruption of TGF-beta receptor II leads to altered regulatory $T$ cell phenotype and spontaneous multiorgan autoimmunity. I Immunol 2012;189:3878-93.

63 Chan OT, Madaio MP, Shlomchik MJ. B cells are required for lupus nephritis in the polygenic, Fas-intact MRL model of systemic autoimmunity. I Immunol 1999; 163:3592-6.

64 Winchester $\mathrm{R}$, Wiesendanger $\mathrm{M}$, Zhang $\mathrm{HZ}$, et al. Immunologic characteristics of intrarenal T cells: trafficking of expanded CD8+ T cell beta-chain clonotypes in progressive lupus nephritis. Arthritis Rheum 2012;64:1589-600.

65 Dolff S, Abdulahad WH, van Dijk MC, et al. Urinary T cells in active lupus nephritis show an effector memory phenotype. Ann Rheum Dis 2010;69:2034-41.

66 Lartigue A, Courville P, Auquit I, et al. Role of TLR9 in anti-nucleosome and anti-DNA antibody production in Ipr mutation-induced murine lupus. I Immunol 2006;177:1349-54.

67 Christensen SR, Shupe J, Nickerson K, et al. Toll-like receptor 7 and TLR9 dictate autoantibody specificity and have opposing inflammatory and regulatory roles in a murine model of lupus. Immunity 2006;25:417-28.

68 Yu P, Wellmann U, Kunder S, et al. Toll-like receptor 9-independent aggravation of glomerulonephritis in a novel model of SLE. Int Immunol 2006;18:1211-19.

69 Hemmi H, Takeuchi O, Kawai T, et al. A Toll-like receptor recognizes bacterial DNA. Nature 2000;408:740-5.

70 Anders HJ, Vielhauer $\mathrm{V}$, Eis $\mathrm{V}$, et al. Activation of toll-like receptor-9 induces progression of renal disease in MRL-Fas(lpr) mice. FASEB J 2004;18:534-6.

71 Pawar RD, Patole PS, Ellwart A, et al. Ligands to nucleic acid-specific toll-like receptors and the onset of lupus nephritis. J Am Soc Nephrol 2006;17:3365-73.

72 Barrat FJ, Meeker T, Gregorio J, et al. Nucleic acids of mammalian origin can act as endogenous ligands for Toll-like receptors and may promote systemic lupus erythematosus. J Exp Med 2005;202:1131-9.

73 Leadbetter EA, Rifkin IR, Hohlbaum AM, et al. Chromatin-lgG complexes activate $B$ cells by dual engagement of IgM and Toll-like receptors. Nature 2002;416:603-7.

74 Krieg AM, Vollmer J. Toll-like receptors 7, 8, and 9: linking innate immunity to autoimmunity. Immunol Rev 2007;220:251-69.

75 Allam R, Anders HJ. The role of innate immunity in autoimmune tissue injury. Curr Opin Rheumatol 2008;20:538-44.

76 Santiago-Raber ML, Dunand-Sauthier I, Wu T, et al. Critical role of TLR7 in the acceleration of systemic lupus erythematosus in TLR9-deficient mice. J Autoimmun 2010;34:339-48

77 Nickerson KM, Christensen SR, Shupe J, et al. TLR9 regulates TLR7- and MyD88-dependent autoantibody production and disease in a murine model of lupus. J Immunol 2010;184:1840-8.

78 Patole PS, Zecher D, Pawar RD, et al. G-rich DNA suppresses systemic lupus. J Am Soc Nephrol 2005;16:3273-80.

79 Pawar RD, Ramanjaneyulu A, Kulkarni OP, et al. Inhibition of Toll-like receptor-7 (TLR-7) or TLR-7 plus TLR-9 attenuates glomerulonephritis and lung injury in experimental lupus. J Am Soc Nephrol 2007;18:1721-31.

80 Barrat FJ, Meeker T, Chan JH, et al. Treatment of lupus-prone mice with a dual inhibitor of TLR7 and TLR9 leads to reduction of autoantibody production and amelioration of disease symptoms. Eur I Immunol 2007;37:3582-6.

81 Dong L, Ito S, Ishii KJ, et al. Suppressive oligodeoxynucleotides delay the onset of glomerulonephritis and prolong survival in lupus-prone NZBXNZW mice. Arthritis Rheum 2005;52:651-8.

82 Kufer TA, Sansonetti PJ. NLR functions beyond pathogen recognition. Nat Immunol 2011;12:121-8. 


\section{ARD NLRP3 and ASC suppress lupus-like autoimmunity by driving the immunosuppressive effects of TGF- $\beta$ receptor signalling}

Maciej Lech, Georg Lorenz, Onkar P Kulkarni, Marian O O Grosser, Nora Stigrot, Murthy N Darisipudi, Roman Günthner, Maximilian W M

Wintergerst, David Anz, Heni Eka Susanti and Hans-Joachim Anders

Ann Rheum Dis 2015 74: 2224-2235 originally published online August 18,2014

doi: 10.1136/annrheumdis-2014-205496

Updated information and services can be found at:

http://ard.bmj.com/content/74/12/2224

These include:

Supplementary Supplementary material can be found at:

Material http://ard.bmj.com/content/suppl/2014/08/16/annrheumdis-2014-2054 96.DC1

References This article cites 82 articles, 32 of which you can access for free at: http://ard.bmj.com/content/74/12/2224\#BIBL

Email alerting Receive free email alerts when new articles cite this article. Sign up in the service box at the top right corner of the online article.

Topic Articles on similar topics can be found in the following collections

Collections

Immunology (including allergy) (5144)

Connective tissue disease (4253)

Inflammation (1251)

Renal medicine (204)

\section{Notes}

To request permissions go to:

http://group.bmj.com/group/rights-licensing/permissions

To order reprints go to:

http://journals.bmj.com/cgi/reprintform

To subscribe to BMJ go to:

http://group.bmj.com/subscribe/ 